\title{
Maximising the benefits of participatory climate adaptation research by understanding and managing the associated challenges and risks
}

\author{
Christopher Cvitanovic ${ }^{1,2^{*}}$, Mark Howden ${ }^{3}$, R.M. Colvin ${ }^{3}$, Albert Norström ${ }^{4}$, Alison M. \\ Meadow $^{5}$, P.F.E Addison ${ }^{6}$
}

\footnotetext{
${ }^{1}$ Australian National Centre for the Public Awareness of Science, Australian National
} University, Canberra, Australia.

${ }^{2}$ Centre for Marine Socioecology, University of Tasmania, Australia.

${ }^{3}$ Climate Change Institute, Australian National University, Canberra, Australia.

${ }^{4}$ Stockholm Resilience Centre, Stockholm University, Sweden.

${ }^{5}$ Institute of the Environment, University of Arizona, Tucson, AZ, US.

${ }^{6}$ Interdisciplinary Centre for Conservation Science, Department of Zoology, University of Oxford, UK, OX1 $3 S Z$.

* Communicating author: Christopher Cvitanovic Telephone: +61 404052278

Email: christopher.cvitanovic@anu.edu.au

\section{Abstract}

4 Participatory research approaches are increasingly advocated as an effective means to 5 produce usable climate adaptation science, and increase the likelihood that it will be beneficially incorporated into decision-making processes. However, while the implementation of participatory research approaches, such as those associated with knowledge co-production, have become increasingly commonplace, to date there has been little consideration given to the challenges and subsequent risks associated with their use. To start to address this gap we review the literature on participatory research in climate 
adaptation science. In doing so we identify and articulate several challenges, and subsequent risks, created by participatory research approaches to adaptation (i) science, (ii) scientists and scientific institutions, (iii) decision-makers and decision-making institutions and (iv) research funders. Based on this we identify seven strategies to help manage these challenges and reduce the associated risks: (a) choose participants carefully; (b) monitor team composition and adjust as necessary; (c) set clear expectations, and agreed conflict resolution mechanisms; (d) use different modes of scientific inquiry that can account for different knowledges and biases; (e) incorporate mechanisms for independent review at all stages of research; (f) reimagine professional development for adaptation researchers, and (g) ensure that appropriate institutional support is in place. These strategies can help to increase the likelihood that participatory research approaches will achieve their goal of generating knowledge that will help society successfully navigate modern day sustainability challenges, such as those posed by climate change.

Keywords: co-production, risk, adaptation science, adaptation scientists, decision-makers, research funders

\section{Introduction}

Anthropogenic climate change is widely considered to be one of the greatest threats facing humanity (e.g. Nicholls and Cazenave 2010; Wheeler and von Braun 2013; Tai et al. 2014; Pecl et al. 2017). Despite global efforts to ameliorate climate changes via the mitigation of greenhouse gases, historical and ongoing emissions mean that impacts from climate change are already occurring and further impacts are now unavoidable (Millar et al. 2017; IPCC 2018). As a result, adaptation has rapidly emerged as one of the biggest global agenda items of the 21st century to help safeguard human well-being and prosperity into the future (Adger et al. 2003; Howden et al. 2007; IPCC 2014).

The growing acknowledgement of the importance of adaptation to address climate variability and change has been accompanied by increasing research effort to support adaptation decision-making (Howden et al. 2014; Frusher et al. 2014). Commonly termed 'adaptation science' (sensu Meinke et al. 2009), much of this research has focused on 
identifying and assessing the threats, risks, uncertainties and opportunities associated with climate change, to generate the knowledge and insights required to effect change in socioecological systems that will increase their adaptive capacity and performance. This is typically achieved by analysing problems without a predefined disciplinary lens so as to allow for the inclusion of multiple perspectives and knowledge systems (scientific- , local- , cultural- , experiential-knowledge, etc.) to generate pathways to support decision-makers in navigating the full suite of socio-ecological complexities and uncertainties associated with adapting to climate change (Haasnoot et al. 2013; Butler et al. 2014; Wise et al. 2014).

Despite the applied nature of adaptation science, and a significant increase in its production over the past two decades, the uptake and integration of new adaptation knowledge into decision-making processes remains limited (e.g. Cvitanovic et al. 2014a; Runhaar et al. 2018). This may, in part, result from the key uncertainties associated with adaptation science, meaning a clear course of action is not necessarily evident to decision-makers. For example, the quantity of academic publications that purport to have decision-relevant insights is high, and includes overlap of topics and conflicting recommendations (O'Leary et al. 2016). Navigating this inefficiency is time-expensive and confusing for decision-makers. When a relevant study is identified, the difficulties continue as there are uncertainties in the global climate models on which adaptation options are premised (Ramirez-Villegas et al. 2013; Grose et al. 2014) and choosing downscaling methods and models that appropriately inform finer scale adaptation options is complex (Hewitson et al, 2014). This complexity is further compounded by the variation in how different researchers define and thus consider adaptation options, which may lead to researchers becoming advocates for their own work rather than promoting the broader array of adaptation options that are actually available (Lacey et al. 2015). Finally, a number of well documented structural impediments and barriers to knowledge exchange between adaptation scientists and decision-makers persist. This includes, but is not limited to, scientific content being 'locked' behind journal paywalls and the time lags between data collection and availability (Cvitanovic et al. 2015a). While such challenges are not unique to climate adaptation science (e.g. Evans et al. 2017), they represent significant barriers to the capacity for decision-makers to implement scienceinformed adaptation measures. 
As a means to produce more usable climate adaptation science (Dilling and Lemos 2011), and increase the likelihood that it will be beneficially incorporated into decision-making processes, there has been a trend towards the implementation of participatory research approaches for generating adaptation science (Meadow et al. 2015; Klenk et al. 2017). While the concept of participatory research can be defined in various ways, we use the term here to describe the process of securing the active involvement of a broad range of stakeholders such as policy-makers and other users in the generation and use of climate adaptation science (following Few et al. 2007). This is based on the belief that when implemented effectively, participatory research approaches enhance the extent to which scientific processes are perceived by stakeholders as credible and legitimate, increasing the potential for the information produced to be trusted and accepted by diverse stakeholder groups (Cash et al. 2006; Reed 2008). An important perspective on participatory research points to the underlying philosophy of the research approach being what differentiates it from more conventional academic research. "[T]he key element of participatory research lies not in methods but in the attitudes of researchers, which in turn determine how, by and for whom research is conceptualized and conducted" (Cornwall and Jewkes 1995 p. 1667). In other words, stakeholders are not just participants in the process, they are the reason for the research process - developing solutions to their problems is the core function of participatory research. Additionally, participatory research approaches can help adaptation science integrate the multiple perspectives and knowledge critical to decision-relevant research so as to tailor adaptation strategies to the needs of research users and the socialecological contexts for its application (Adger et al. 2005; Cornell et al. 2013).

Despite increased advocacy for the implementation of participatory research approaches in relation to climate adaptation, our understanding has remained largely uncritical (Lemos et al. 2018). While significant and important advances have been made in relation to (i) developing a typology of participatory research approaches (e.g. Meadow et al. 2015) and (ii) identifying the underpinning characteristics that are required for the implementation of successful participatory research approaches (e.g. van Kerkhoff and Lebel 2015; Wyborn 2015; Beier et al. 2016), comparatively fewer studies in the climate adaptation literature 
have sought to critically evaluate or understand the extent to which participatory research approaches pose additional challenges and risk to participants involved in the process (but see Harris and Lyon 2014; Gaziulusoy et al. 2016). Understanding the suite of potential challenges associated with participatory research approaches is critical for identifying the subsequent risks, and developing strategies to manage these so as to enhance the likelihood that participatory climate adaptation research will meet its desired goal of helping society successfully navigate modern day climate challenges.

To address this gap, we draw on the published literature (via a narrative review informed by our own experiences working within climate adaptation participatory research projects) to identify and explicate potential challenges created through participatory research to climate adaptation science, key actors groups including scientists and policy-makers, and research funders. While we acknowledge that there are other societal actors who can (and should) play a critical role in participatory adaptation research processes, for whom there are also risks that should be considered, we choose to focus on these three types of actors in this instance to allow for the detailed exploration of key issues and to identify specific strategies for managing the identified risks. We hope that by starting to explore these issues we will encourage researchers and practitioners to undertake future research to understand how the risks associated with participatory research are increased for other actors, and identify strategies for how they can be managed.

In writing this manuscript we acknowledge that the interface between science and policy is highly contextual and varies widely across geographies, cultures and temporal scales. Our goal in writing this manuscript is not to provide an in-depth analysis at any of these specific interfaces, but rather, to identify the potential challenges associated with participatory research more generally, and propose strategies for managing them, to help maximise the benefits resulting from participatory climate adaptation research processes (following Lacey et al. 2018). In this article we characterise these challenges through the language of 'risk', as this infers that the challenges can be both known and managed, though the level of concern about risk will differ depending on how it is perceived (e.g. Slovic 1987). We also 
acknowledge that this manuscript is informed by our personal experiences working primarily within Western cultures and developed nations, and thus the recommendations are most applicable within comparable research contexts, with potentially limited application to other contexts. To this end, we encourage other researchers and practitioners who are engaging in participatory adaptation research in different cultural settings and sectors to build on our efforts here and similarly share their experiences. Finally, while we focus our examples on climate adaptation, many of the challenges identified, and solutions posed, are likely to be applicable across all fields of participatory sustainability science.

We first (Section 2) provide a brief overview of participatory research to understand its origins and how it has evolved into practice in relation to climate adaptation research. This includes a review of the posited benefits associated with the implementation of participatory research approaches. Then (Section 3), we explore the potential challenges and risks associated with participatory research approaches to adaptation (i) science, (ii) scientists and scientific institutions, (iii) decision-makers and decision-making institutions, and (iv) research funders. Finally, in Section 4, we identify a range of strategies for managing the risks to increase the likelihood of success for participatory climate adaptation research.

\section{Overview of participatory research}

\subsection{A short history of participatory research}

Participatory research is an approach that involves the active engagement of diverse stakeholders in the research process. Participatory approaches to research arose as early as the 1940s (Lewin 1946; Tax 1958) as a response to positivistic notions in the sciences that excluded many voices and sources of knowledge, particularly local, indigenous, gender, and ethnic minority knowledges (Brown and Tandon 1983; Park et al. 1993; Greenwood and Levin 2007; Wallerstein and Duran 2008). A set of research approaches - including action research, participatory action research, practitioner research, emancipatory research, and community-based participatory research - has developed since that time to address a 
variety of social, environmental and health problems facing on-the-ground stakeholders and decision-makers. The whole suite of participatory research approaches intends to make research both more democratic, through stakeholder involvement, and impactful, by tying it to actions that benefit those stakeholders (Reason and Bradbury 2008a; Wallerstein and Duran 2008).

With the overarching goal of enabling informed change by engaging different stakeholder groups within research activities (reviewed by Khanlou and Peter 2005), participatory research focuses on engaging decision-makers and other stakeholders in research, not as subjects, but as co-producers of knowledge (Greenwood and Levin 2007; Reason and Bradbury 2008b). While this aspiration for egalitarian partnerships is not always met in practice (Wiber et al., 2004), the principles underlying this branch of research centre on notions of equality, co-production, and social and environmental justice, enacted through a mutually respectful and beneficial relationship between researchers and research stakeholders.

Stakeholder involvement in research can take a number of forms starting with low levels of engagement such as providing data for a research project or providing evaluative feedback on research products (i.e., consultation), to higher order engagement where research stakeholders inform the development of research questions and contribute to the setting of research agendas (Figure 1) (Reed 2017). Consultative approaches, however, can be limited in their use given that stakeholders often remain a source of information for use by researchers, rather than partners in the research process. As a result, these approaches do not guarantee the full development of the relationship between the producers and users of research, potentially undermining the extent to which the benefits of participation are conferred (see Section 2.2). 


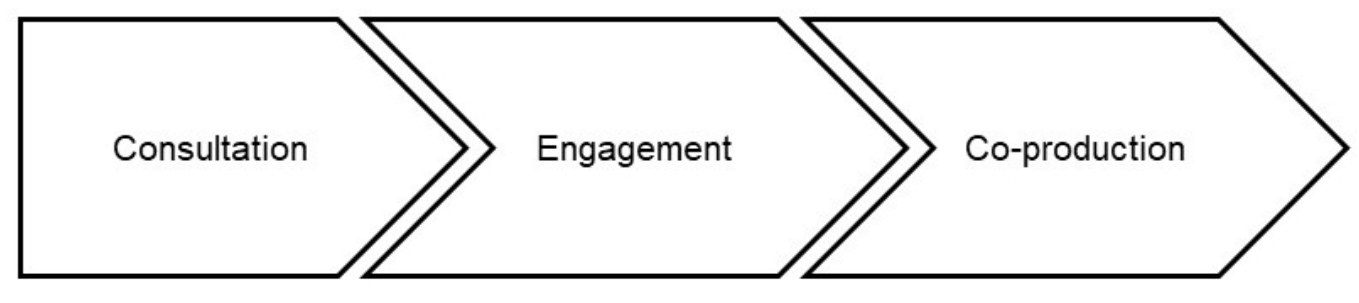

Stakeholders as inputs

Stakeholders as partners

Figure 1: Conceptual representation showing how the involvement of stakeholders in participatory research can take a variety of forms from consultation to co-production.

It was these shortcomings that encouraged the development of the broad field of participatory research. The practice developed largely in the social and health sciences, but in more recent decades, the practice has been explored in the biophysical and environmental sciences as a way to address increasingly complex environmental problems like climate change adaptation. Co-production of knowledge (Jasanoff 2004) has become a common term within the climate change adaptation field used to capture the idea that solutions to complex problems require interaction and co-production of solutions between science (researchers) and society (stakeholders). In this model, researchers and research stakeholders interact directly via trusting relationships and with shared goals. A recent review of the literature by Bremer and Meisch (2017) showed significant increases in the number of publications relating to climate change and co-production over the past two decades. Similarly, Meadow et al. (2015) also note the proliferation of supposedly coproduced climate knowledge.

Participatory research can also be facilitated through intermediaries such as boundary organisations (Guston 2001) and knowledge brokers (Meyer 2010). While conceptualised differently across sectors and settings, the key feature of these intermediaries is to facilitate the exchange of knowledge between various stakeholders, including researchers, practitioners and decision-makers. This is achieved by developing networks among these groups of stakeholders and facilitating their active involvement within research activities (Reinecke 2015). Indeed, the use of intermediaries in relation to climate challenges has 
increased, for example, in the United States with Jacobs (2014) identifying the NOAA Regional Integrated Sciences and Assessments program, the Climate Adaptation Science Centres funded by the Department of the Interior, and the 'climate hubs' of the US Department of Agriculture as recent examples of successful boundary organisations (Bednarek et al. 2018). Similarly, in Australia, recent empirical evidence has shown that a single knowledge broker was able to facilitate a cohesive network of climate scientists and decision-makers to promote increased participation and knowledge sharing (Cvitanovic et al. 2017).

Finally, participatory research can also be facilitated via novel institutional structures that 'embed' scientists within decision-making agencies, or vice versa (sensu Cvitanovic et al. 2015a). For example, Cook et al. (2013) posit that if decision-making agencies were to permanently embed research scientists within their organisations it would improve the likelihood that priority knowledge gaps will be filled, with the information quickly spreading among decision-makers and informing decisions. In this way the idea of embedding builds on that of knowledge co-production, in that it allows for decision-makers and scientists to collaborate more intensively through all aspects of both the scientific and decision-making processes. Furthermore, the embedding approach facilitates the implementation of long term participatory research activities and strategic collaboration across timescales better aligned with the challenges presented by climate change (i.e. beyond the scope of a single project) (Doubleday and Wilsdon 2012; Reed et al. 2014).

In summary, the core goals of participatory research are to co-produce knowledge and solutions with, and for, decision-makers and other stakeholders. In practice, a continuum of participation may occur, from stakeholders as inputs to research projects through models of co-production where the stakeholders actively partner with researchers in the research process, based on the specific questions and context of any given research project. Means such as the use of intermediaries and boundary organisations and institutional embedding can facilitate the novel and more intensive approaches to participatory research. 
Alongside the development and implementation of the different approaches to participatory research, an extensive body of literature has also emerged outlining a range of benefits associated with their application. One key benefit is that participatory research approaches overcome known barriers to knowledge exchange among scientists and decision-makers to support evidenced-informed decision-making (review by Cvitanovic et al. 2015a). In this section we provide a brief overview of these benefits.

First, participatory research approaches can be an effective way to make science more accessible to decision-makers and facilitate its incorporation in the decision-making processes. For example, studies across different environmental sectors have shown that on average it takes more than three years for scientific articles to be published following data collection (Fazey et al. 2005), and thus information may be out of date and less useful to decision-makers by the time it is made available (Linklater, 2003; Cvitanovic et al. 2016b). Furthermore, even when scientific knowledge does become available the majority is retained behind journal subscription paywalls which many decision-making agencies cannot afford (e.g. Cvitanovic et al, 2014b), thus further limiting its accessibility to, and utility in, decision-making processes. To illustrate, a recent analysis by Bornmann et al. (2016) found that only $1.2 \%$ of published climate change research has been cited in policy documents. Participatory research approaches are believed to help overcome these barriers, as the direct involvement of decision-makers and other end-users in the scientific process ensures that the research undertaken is solution-driven and useful for the decision-making context (Bednarek et al 2018). Additionally, these approaches can help decision-makers develop a real-time and in-depth understanding of the research content, which they can then disseminate quickly and effectively throughout their social networks and organisations as the information emerges (Reed et al. 2014).

Building on this, participatory research approaches are believed to increase the extent to which the outcomes of scientific research are perceived by decision-makers as salient, credible and legitimate (Cash et al. 2003). In this regard, salience describes the extent to 
which the research outcomes are relevant to decision-makers and specific decision-making contexts, taking into consideration their specific information needs and institutional operating environments (Cash and Moser 2000). Credibility refers to the extent to which scientific outputs and outcomes are perceived by decision-makers as accurate, valid, robust and of high quality (Cash and Buizer, 2005; Salter et al. 2010) while legitimacy describes the extent to which the knowledge producers (i.e. adaptation researchers) are considered to be bias free and thus trustworthy by decision-makers (Deelstra et al., 2003). In combination, it is believed that these three traits increase the likelihood that scientific outcomes will be incorporated into decision-making processes (Cash et al. 2003), particularly in relation to complex and contested issues such as those associated with climate change and the array of available adaptation options to decision-makers. For example, as detailed in Lacey et al. (2015), there are numerous uncertainties associated with how adaptation options are selected for implementation, such as the choice of appropriate methods for downscaling global or regional models to inform adaptation at the local scale (Hewitson et al., 2014). This, in combination with the ways in which different researchers define and respond to adaptation (e.g. considering technological innovation versus institutional change), creates the risk that researchers may become advocates for their own work without full transparency that their recommendations represent only a subset of the available knowledge and adaptation options that are available. In such cases there is the potential that adaptation science will not be utilised, or will lead to suboptimal outcomes, thus highlighting the importance of salience, credibility and legitimacy in relation to adaptation science.

Next, participatory research approaches can facilitate the inclusion of multiple knowledge systems into decision-making processes (Mauser et al. 2013; Tengö et al. 2017). This is important given that scientific knowledge is only one form of knowledge system that can contribute to informing adaptation decision-making processes, and in recognition that adaptation science is most useful to, and trusted by, decision-makers when considered in conjunction with other forms of knowledge (Cornell et al. 2013; Cvitanovic et al. 2014a). For example, the inclusion of local and cultural knowledge is critical for identifying the most appropriate and culturally sensitive fine-scale adaptation options, and subsequently for 
understanding how to engage with local communities to promote their uptake (Reid et al. 2009; Gearheard et al. 2010; Naess 2012; Boillat and Berkes 2013). Similarly, the inclusion of experiential knowledge is believed to enhance the likely success of decision-making processes as it allows those engaged in participatory research approaches to learn from previous successes and failures (e.g. in relation to the communication and subsequent acceptance of adaptation options by end-users), thus increasing the potential for success of decision-making processes (Fazey et al. 2006). Finally, the integration of expert knowledge through formal expert elicitation techniques can be used effectively to support decisionmaking under uncertainty and in scenario modelling of uncertain future events, particularly when quantitative scientific evidence is lacking (Hemming et al. 2017; Martin et al. 2012). Thus, bridging diverse knowledge systems through participatory research has also been shown to generate innovative, more inclusive and equitable solutions to sustainability problems, such as those arising from climate change (Mauser et al. 2013).

Finally, participatory research approaches are recognised for their ability to foster learning among participants (reviewed by Gupta 2016), which we define as 'the process of cognitive change leading to behavioural change, which can manifest at either individual or collective scales' (following Newig et al. 2010). Essential to this shared learning via participatory research is the direct interface between researchers and research stakeholders. By creating a space where the research 'producer' and 'user' build meaningful relationships that break down the intergroup divide - turning 'us and them' into 'we' - researchers and research stakeholders are more likely to experience trust (Lacey et al. 2018), a sense of shared identity and purpose (Fielding and Hornsey 2016; Colvin et al. 2015), and social influence that increases "receptiveness to the views of those whom we regard as 'one of us'" (Mols et al. 2015, pp.89-90). This relationship building enables learning in the immediate term (e.g. via a distinct project) and in the longer-term (e.g. via ongoing collaboration and interaction) ultimately enhancing outcomes for climate adaptation researchers and research stakeholders alike. Learning is considered particularly important for navigating the uncertain, complex and synergistic challenges presented to society by climate change (Sardar 2010; Parrott and Meyer 2012; Picketts 2018), as it underpins the extent to which 
decision-makers and their associated governing institutions can respond rapidly, adaptively and flexibly to change (Fazey et al. 2007).

\section{Challenges and subsequent risks of participatory climate adaptation research}

Arguably, all applied research - in which our suppositions and experiments are subject to real-world tests - is a risky endeavour. We remove the protective boundaries of a tightly controlled laboratory and grapple with the messy world in which science and society interact and intermix constantly. However, participatory research poses some additional challenges because it actively includes multiple perspectives, voices and values in ways that make data collection, analysis and interpretation much more complicated than the traditional laboratory situation. In some cases, these additional challenges may also confer additional risks to the actors taking part in the participatory research process. Thus, as the use of participatory research approaches grows in climate adaptation work, we must consider the challenges and risks in ways that have not yet been done within the climate adaptation community, so as to identify options for managing them, in turn ensuring that adaptation science can fulfil its objective of helping society achieve the transformative changes that are required. To this end, in this section we draw on the existing literature and our own experiences operating in participatory research projects to undertake a critical examination of the challenges associated with participatory research approaches and the risks that they may confer. While our list is not exhaustive, it serves to highlight some of the key challenges associated with participatory research processes about which participants should be mindful.

\subsection{Challenges to the scientific process}

\subsubsection{Compromised scientific integrity}

First, participatory research approaches may generate some additional challenges and risks to the scientific process with regards to both the 'quality' and 'utility' of the scientific outcomes, as are commonly understood in the natural and physical sciences where much climate research is based. Every participant engaging in participatory research approaches 
has a set of beliefs about what constitutes knowledge, how it is produced and how it should be applied (i.e. their epistemological perspective) (Blythe et al., 2017). Participatory research depends on these multiple perspectives - including the unique perspective of the researchers - to increase the external validity of research (i.e. its applicability to solving realworld problems) (Green et al. 2009). However, balancing and incorporating multiple, and possibly contradictory, perspectives in ways that maintain the credibility of the science poses both philosophical and practical challenges.

The inclusion of multiple participants within the research process and the associated combination of knowledge systems, may appear to compromise the actual and/or perceived integrity of the scientific outputs (Mauser et al. 2013; King and O'Meara 2018). For example, while it is generally argued that addressing contemporary climate adaptation challenges requires the integration of knowledge systems (e.g. local knowledge, experiential knowledge, cultural knowledge, etc.), non-scientific knowledge can be perceived by some as more susceptible to bias or lacking in credibility. Thus, the inclusion of a diversity of knowledge systems, without careful and ethical research practices, presents a real or "perceived" risk that biased or un-interrogated beliefs could undermine the perceived rigour of research outputs. This, in turn, could reduce the extent to which decision-makers trust the research outcomes and/or outputs, making it less likely that they incorporate them into their decision-making processes.

\subsection{2 'Containment' of actors}

Power imbalances can also play a role in the ways that multiple and diverse perspectives are incorporated credibly in a participatory research process (Few et al. 2007). For example, where epistemological perspectives among participants are mutually exclusive, some forms of knowledge (e.g. scientific, experiential, local) and research methodologies (e.g. quantitative vs qualitative vs mixed-methods approaches) may be disregarded or distrusted by some research participants (Blythe et al. 2017). This has the potential to disrupt the collaborative research effort, and lead to the dominance of one knowledge system over the others (Balvanera et al. 2017). In these situations, the more 'powerful' individuals or groups 
can consciously or subconsciously steer participation towards support for a specific epistemology, method, or even a predetermined outcome, by forging tactical alliances and blocking dissent; termed 'containment' of participation (Few 2001; 2003). This means that research outcomes are less likely to have been informed by the full suite of available knowledge, reducing its usefulness to assist in informing adaptation decision-making processes, or potentially leading to maladaptive decision-making processes.

Further, in many cases of participatory research it is those who are managing the participatory process that are in the privileged position of deciding who is considered a legitimate participant and who is not, in turn potentially elevating some perspectives and excluding others (Colvin et al. 2016). Other types of power, too, can influence the success of participatory research. For example, Reed (2016) encourages researchers to consider their relative power in participatory processes, including their situational power (formal, hierarchical, power), social power (privilege due to gender, race, sexuality etc.), personal power (personal traits such as trustworthiness, charisma) and transpersonal power (access to powerful others). Reflecting on power dynamics in a participatory research setting can identify where the reality of - or perceptions about - power creates expectations that can be conducive or inhibiting to effective participatory research. Where power is used to create an unfair advantage for certain groups or ideas, whether intentionally or unintentionally, it puts the legitimacy of the process and the credibility of the science at risk, limiting its utility for decision-making processes and broader societal responses to adaptation.

\subsubsection{Tokenistic engagement}

There is also a risk that participants could simply be engaged within participatory research approaches on a tokenistic level (Arnstein 1969) - in which case the research may no longer be considered as participatory. For example, as calls for science to fulfil its societal obligations have increased (e.g. Lubchenco 1998), so too has the requirement by research funders for research proposals to be 'transdisciplinary', and actively engage decisionmakers. It is now commonplace that research proposals are submitted describing a 'high level participation' between the research team and decision-makers (e.g. Watermeyer and 
Hedgecoe 2016). However, the extent to which high levels of participation occur in practice may be limited, compromising the overall success of the process and reducing the validity of the outputs and outcomes.

\subsection{Challenges for adaptation scientists and scientific institutions}

\subsubsection{Compromised individual integrity}

Participatory research approaches can also present significant challenges to adaptation scientists. For example, as outlined in section 3.1, the inclusion of multiple epistemological perspectives that results from participatory research approaches has the potential to compromise both the actual and/or perceived integrity of the scientific outputs (e.g. Supran and Oreskes 2017; King and O'Meara 2018). In this respect, social science practitioners of participatory research and those beginning to use the approach in climate adaptation are in agreement - the perception from other researchers that applied, participatory research is somehow less rigorous or "scientific" is a recurring theme and challenge (Greenwood and Levin 2007; Polanyi and Cockburn 2003; Schensul et al. 2014). This has the potential to adversely impact the individual reputation of researchers (e.g. reputational risk) engaged in participatory research processes among their peers and decision-makers in the field. This may, in turn, limit their opportunity to collaborate with peers, or the extent to which their research outputs are trusted and used in decision-making processes outside of the group with whom the researchers directly collaborated with on the participatory research project.

\subsubsection{Impacts on career progression}

Current incentive systems in academia result in a researcher's reputation being largely dependent on their academic achievements (e.g. quality of their peer-reviewed publications and funding success). It has been shown that research involving multiple epistemological perspectives has consistently lower funding success than more traditional modes of research (Bromham et al. 2016), and is typically more challenging to publish in top tier scientific journals as many journals are discipline-specific and those that are not find it difficult to find reviewers who span multiple epistemological perspectives (Campbell 2005; 
475 Rafols et al. 2012). Given that funding success and publication in top tier journals remain a

476 key measure of academic performance (e.g. Cvitanovic et al. 2015b), utilising participatory

477 research approaches can confer risks to adaptation scientists via impacts to their job

478 security, career progression and success in science.

The implementation of participatory research approaches also has significant complexity and transaction costs (Beier et al. 2016; Balvanera et al. 2017) that can present a number of challenges to career progression among adaptation scientists. Firstly, negotiating the various perspectives of different stakeholders involved in the process (and accounting for their institutional requirements such as approvals and internal review processes) can be time consuming (Polk 2015). Time spent traveling and attending meetings in addition to the standard travel requirements of research (e.g. field work) also means time away from other competing academic demands (Hoeft et al. 2014). These transaction costs present a risk to scientists as they could ultimately impede progress of scientific outputs by extending the time before publication of results, which as described above, can have subsequent impacts on career success and progression. In contexts where there is poor institutional acceptance of, and support for, extended timeframes associated with participatory research, it may lead to the perception that scientists are 'under-delivering', once again adversely affecting the ability of adaptation researchers to seek permanency or promotion.

\subsubsection{Impacts on personal well-being}

Closely related to the above, increased process complexity and the associated transaction costs can also impact on the work-life balance of adaptation scientists (Campos-Arceiz et al. 2013). For example, increased travel requirements and attendance at prolonged meetings and workshops can limit the time that adaptation scientists spend with family and friends. This, in turn, may lead to strained, or lost, relationships. Long and non-typical working hours, such as those associated with excessive travel, are also known to be risk factors for depression and anxiety (Kleppa et al. 2008; Virtanen et al. 2011). 
Furthermore, the range of skills and experiences required to navigate and negotiate complex participatory processes (ability to read social cues, navigate complex political settings, etc.) are not taught as part of traditional academic training programs (Bernstein et al. 2017) or considered legitimate forms of academic scholarship (Jacobson et al. 2004). As such, some adaptation researchers might find engaging in such processes particularly challenging and stressful, or even unnecessary, thus limiting their levels of professional confidence and satisfaction. This compounds with existing stressors on personal wellbeing for researchers, which in a more standard model of science, are already not insignificant (Reevy and Deason 2014).

\subsubsection{Decreased 'trustworthiness'}

Engaging in participatory research approaches may also limit the extent to which adaptation researchers are perceived outside of their group as 'honest brokers' (sensu Pielke 2007). As described by Pielke (2007), the notion of honest broker describes a sub-set of scientists who do not advocate for a single cause or pre-determined outcome, but rather consider the full suite of available information to provide factual, empirically-based advice that does not reflect their individual research or epistemological perspective.

In instances where adaptation researchers work closely with specific decision-makers for long periods of time, they might be perceived by other stakeholders and end-users as losing their objectivity, lessening the extent to which they are considered an honest broker, and thus, their potential impact on decision-making processes more broadly. For example, adaptation researchers (and by association their colleagues and institutions) who have collaborated closely with industry may not be viewed as credible by environmental NGO stakeholders or other scientists and institutions who choose not to engage with industry, and vice versa. In such situations, the boundary between researcher and research stakeholder blur to the point where perceptions about the research stakeholder's motives, conduct and credibility are transferred to the researcher, regardless of the nature of scientific integrity and rigour underpinning the researcher's work. 
Participatory research approaches can also present several challenges and risks to decisionmakers that engage in them. Firstly, they can increase the likelihood of situations whereby an individual scientist (or group of scientists) 'capture' decision-makers who then continue to support and fund a specific stream of research that aligns to the disciplinary or epistemological lens of that specific scientist group (Lacey et al. 2018). This can have adverse impacts for both individual decision-makers and the broader decision-making agency. For example, for highly complex and uncertain challenges such as those presented by climate change, a focus on singular dimensions of the issue may lead to missed opportunities or even maladaptation (Lacey et al. 2015). This may also lead to increased scrutiny of the individual decision-makers engaged within the participatory research process, and of the broader decision-making agency. This has the potential to adversely impact individual careers and cause individual distress, while potentially also impacting broader societal support for, and trust in, the decision-making institution.

\subsubsection{Loss of perceived legitimacy by public}

Building on the above, when dealing with controversial and complex issues such as those associated with climate adaptation (Boykoff 2007), the likelihood of divergent perspectives among participants is heightened. This may lead to dissent among participants and conflict may arise (Colvin et al. 2015). In such cases there is the risk that adaptation researchers, who are not bound by organisational limitations, may speak out publicly in opposition to the decision-makers' public position, leading to a loss of public support for the agency (Picketts 2018). Where this occurs there are also risks to individual decision-makers associated with distress and mental health, as well as to the broader decision-making agency by affecting the extent to which they are perceived as legitimate by their stakeholders and the broader public (Tyler 2006). However, we acknowledge the important role of researchers in challenging decisions that may go against best available evidence or fail to represent the 
public good. Nevertheless, when these dynamics arise in a participatory research setting the potential risk to decision-makers is heightened. From the decision-makers' perspective, inviting researchers into the decision-making process necessarily makes the decision-maker vulnerable to researchers with privileged knowledge of the decision context and process using that knowledge to act as powerful adversaries in the public sphere.

\subsection{Challenges to adaptation research funders}

\subsubsection{Increased (potentially unjustifiable) costs}

Finally, participatory research approaches can also present additional challenges to funders of climate adaptation research. For example, the increased number of participants, who are also likely to be geographically dispersed, associated with participatory research approaches can lead to increased implementation costs (which is the cost of coordinating implementation and the potential opportunity cost of implementation failure) (Birner and Wittmer 2004). At the same time it will also increase decision-making costs (cost of acquiring information, cost of coordinating decision making and decision-failure cost) and production costs (technical measures needed to manage the research or implementation of the outputs) (Birner and Wittmer 2004; Sutherland et al. 2017). Thus, where the benefits achieved through participatory research approaches do not outweigh their additional costs the funders are likely to be increasingly scrutinised with potential impacts to their public credibility, particularly in instances where funding is provided via public monies (e.g. government grant schemes).

Compounding this risk is that many collaborative processes necessitate expenses that may be more open to public critique, compared with traditional laboratory-related costs. This includes costs from catering for workshops and meetings, and the travel and accommodation associated with relationship building as opposed to a physically tangible deliverable. The potential intangibility of the activities, as well as the costs, associated with participatory research may create difficulties for research funders in justifying their funding choices to relevant actors. 


\section{Strategies to manage risk in participatory research}

593 Despite widespread advocacy for the implementation of participatory research approaches

594 in relation to climate adaptation, we have outlined how they can also present significant 595 challenges and risks to adaptation science, scientists, decision-makers, and funders.

596 Identifying and implementing strategies to reduce and manage these risks is critical to 597 ensure that the perceived benefits of participation are realised. In this section, we review 598 the literature from other sectors where participatory research approaches are commonly 599 implemented (e.g. the medical sector and private sector), to provide insights and strategies 600 for how to manage risk and maximise the potential for success of participatory climate 601 adaptation research (Figure 2; Table 1). In doing so, however, we reiterate our earlier point that these strategies have been informed by the various experiences of the author group who primarily work within Western and developed cultures and contexts. Thus, their applicability is best suited in comparable contexts, and future work is needed to understand how they could also be applied across broader cultures and contexts, or what other mechanisms are available for other contexts.

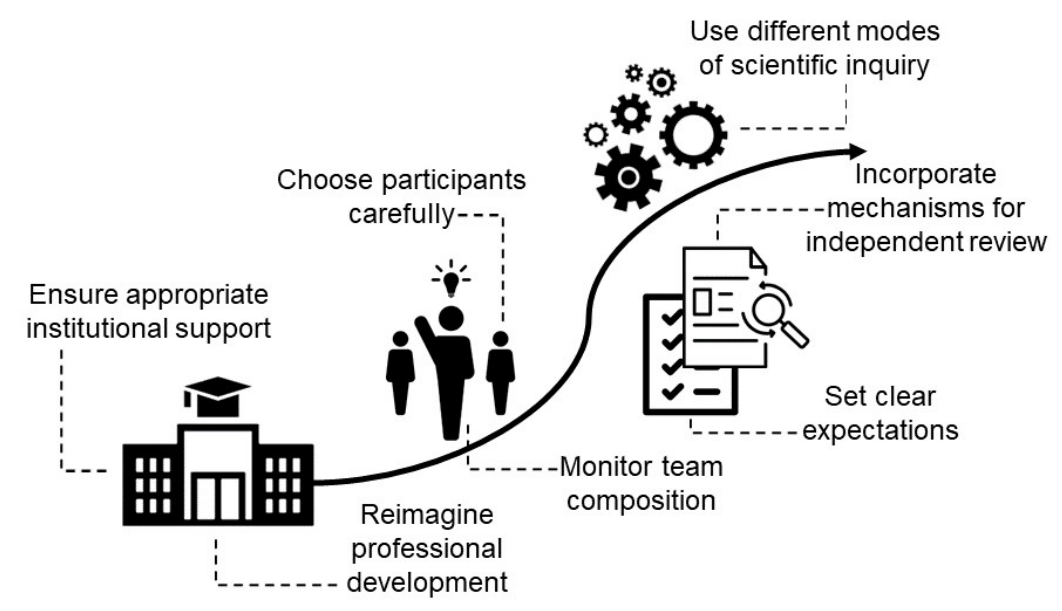

Figure 2: Visual representation of the seven strategies that can be used to manage the challenges and risks of participatory adaptation research. with participatory research approaches is largely dependent on the composition of 
the group. However, it has been shown that achieving an appropriate balance in group composition is highly variable according to individual characteristics of the participants as well as the social and political context within which the science is to be produced (e.g. Eckley 2002; Farrell and Jäger 2005). While it is difficult and sometimes undesirable to manipulate and/or change social or political contexts, steps can be taken to ensure that participants display the required individual attributes to minimise risk and maximise the likelihood of success (Timmings et al. 2016). For example, it is critical that all participants, despite their individual epistemological perspectives, are open to the perspective and worldviews of the other participants (Eckley et al. 2001; Evans and Cvitanovic 2018). It is also critical that the group is sufficiently context specific to represent the perspectives that are relevant to the research or decision context, and that representation across groups is balanced to reduce the likelihood of a power imbalance. In sum, it is important to ensure that access to participatory research is open to all stakeholders with appropriate expertise, reflecting principles of equity of access and inclusion. However, given the necessity of inter-personal trust, it is also important to take seriously the need to address and appropriately deal with participants who may undermine or exclude other participants from a different background during the process (whether it be personal, disciplinary, or otherwise).

Adopting approaches which explicate identification processes is, therefore, important for ensuring all relevant participants are identified, not just those who may be familiar or easily accessible to the adaptation scientists or decision-makers (Colvin et al. 2016). To achieve this, in developing teams the initiators (be they adaptation researchers or decision-makers) could use stakeholder analysis techniques (see review by Reed 2008) to identify all relevant (i.e. context specific) stakeholders, the existing relationships that exist among them and the potential level of influence and/or power that they might have in the group.

Appropriate researcher training and capacity development is also a key consideration (Hegger and Dieperink 2014; Meadow et al. in review; Wiek et al. 2011). Indeed, inadequate preparation and training of researchers to conduct 
participatory research is a key risk to the process (Grant et al. 2008). Given that effective participatory research depends on transparent and trusting relationships among all team members, it is critical that researchers have adequate communication, facilitation and group-process skills in addition to their research and academic skills (Grant et al 2008; Addison et al 2013). Further, Cheruvelil et al. (2014) highlight the ways in which teamwork training (via both formal and informal avenues) can promote a collaborative environment and increase the likelihood of success in solving complex environmental challenges. Thus, by incorporating specific skills that support team building initiatives and activities throughout the project (e.g.

b) Monitor team composition and adjust: Despite best efforts to ameliorate risks via the careful selection of participants, participatory research approaches can be highly informal team meetings, formal team and trust-building initiatives, etc.), collaboration and productivity can be enhanced over the duration of the project. dynamic over time, for example; given changing social and political settings, changes in the personal circumstances of participants, or conflicts that may arise (Sarkki et al. 2014). As such, it is critical that the team composition, and the extent to which it is functioning effectively, is monitored and adjusted as needed over time (Djenontin and Meadow 2018). This could be achieved via the implementation of longitudinal social network analysis (e.g. Cvitanovic et al. 2017), which is a cost effective approach to monitor the role and influence of the various participants according to their 'position' within the overall network, and how these change (Crona and Bodin 2006; Bodin and Crona 2009). Schulz et al. (2003) also recommend annual surveys to monitor group dynamics and adjust processes to ensure projects remain productive. Such surveys may include evaluation of whether team members feel they are part of one coherent whole (i.e. a 'we') or see themselves as belonging to a number of fractured groups (i.e. 'us and them') (e.g. Haslam et al. 2003). Doing so will allow for the early identification of potential issues that may emerge, such as 'powerful' individuals or intergroup conflict, so that collective action can be taken to remedy the situation. 
Furthermore, ongoing monitoring of the group composition should include regular (e.g. annual) stakeholder analyses to assess whether the participants represent all the relevant stakeholders. This will ensure that even as social and political situations change, all relevant stakeholders groups are correctly represented. While individual team members may change over time in response to the broader needs of the group, because participatory research often depends on long-term relationships, "the goal ... is to generate networks that are sufficiently strong that members can come and go without threatening the cohesiveness of the overall partnership" (Austin 2004, P. 427).

c) Set clear expectations and agreed conflict resolution mechanisms: Once the team has been identified, it is important to collectively set and agree upon the expectations associated with the participatory research effort. These expectations should look beyond simply agreeing on joint outputs of the research by also focusing on expectations relating to individual behaviours and conflict resolution mechanisms for the entire research process. Indeed, developing conflict resolution mechanisms for highly collaborative groups such as those embodied by participatory research approaches is particularly challenging, given a potential lack of access to external and fully independent conflict-resolution mechanisms (Alston et al. 1999). Thus, agreeing on and documenting a shared set of conflict resolution options at the outset is critical (Margerum 2002). For example, establishing multi-stakeholder decision-making groups under specific and explicit rules around collaboration and the necessity for productive outcomes was found to facilitate effective participatory decision-making in high-conflict settings (Colvin et al. 2015). Furthermore, given that the majority of climate adaptation research requires research ethics approval, conflict resolution measures could be included within ethics applications so that there are options to seek external support should the conflict not be able to be resolved among the members of the participatory research process (Khanlou and Peter, 2005).

\section{d) Utilise different modes of scientific inquiry to address different knowledges and}

biases: As highlighted through the experiences of social science practitioners of 
participatory research, reflexive and interpretive modes of inquiry that directly consider the tensions between different viewpoints as part of the research process should be used (Wallerstein and Duran 2008; Fazey et al. 2018). That is, treating participatory research as a research practice, not a public participation effort - in order to balance and integrate multiple perspectives. For example, using multiple lines of inquiry such as one-on-one interviews, focus groups, surveys and participant observation helps researchers better understand how and why the multiple perspectives exist and provides opportunities to triangulate information and accounts received from participants. This process of triangulation and reflection can also be combined with an iterative and reflexive analysis process involving researchers and stakeholders to ensure that power imbalances are managed and that the different knowledge systems are equally accounted for (e.g. van Kerkhoff and Pilbeam 2017).

Reflective and interpretive modes of scientific enquiry also point to the need for researchers to consciously encourage all participants to examine their values and views as part of understanding the larger problem and potential solutions. Specifically, and as described by Huntjens et al. (2014), the researcher should play a different role from the stakeholders in order to ensure that the added value of the researcher in the process is maintained. One aspect of that role, according to Greenwood and Levin (2007, P. 54) is that action researchers are "obligated to question [local stakeholders], press their logics and interpretations ..." and "reflect back to the local group things about them, including criticism of their own perspectives or habits, in a way that is experienced as supportive rather than negatively critical or domineering". Tools like facilitation can also be used to help the group as a whole avoid overemphasis of a single perspective or knowledge base (Mackewn 2008).

In addition to reflexive and interpretive modes of inquiry, in collaborations designed to support decision-makers through a participatory process, other approaches such as structured decision-making can be used. Structured decision-making involves structured processes for scientists to follow from defining the decision context 
through to exploring and implementing adaptation options, monitoring and evaluating effectiveness of implemented adaptation activities (Addison et al. 2013). Most importantly these approaches involve facilitation techniques and tools to elicit carefully both factual information (e.g. about the state of the environment) and values (e.g. individual priorities or preferences), whilst accounting for biases and uncertainty within these knowledge systems (e.g., Addison et al. 2013; Hemming et

\section{e) Incorporate mechanisms for independent review at all stages of research: In} addition to the strategies outlined above that can be implemented by the research team itself, risk in participatory research approaches can be further managed via independent reviews. As reviewed by Khanlou and Peter (2005), independent reviews ensure that individuals who are unaffiliated with the research project have the opportunity to evaluate the project to ensure that it meets its desired scientific outcomes in an ethical manner, further reducing any potential conflict of interest. In many cases, participatory research will be reviewed by human ethics review boards as part of standard academic practices. Indeed, it is for this reason that independent reviews are now common place within participatory medical research (Emanuel et al. 2000). To be most effective, independent reviews should be undertaken by multiple individuals throughout the scientific process, from the conceptual and design phase, through to the implementation of the research and the development of subsequent scientific outputs.

Independent reviews should not only be output focused, but also provide an evaluative mechanism on the overall functioning and dynamics of the team and various participants (e.g. Trimble and Lázaro 2014). It is also important to ensure that reviewers are familiar with the processes and practices of participatory research so as to avoid having the project evaluated inappropriately based on a misunderstanding of the credibility of participatory research (as discussed in section 3.1) (Polanyi and Cockburn 2003). Where independent reviews find that teams are not functioning effectively and risk has been created, steps should be taken to remedy the problem, by returning to the set of behavioural expectations agreed 
upon at the onset of the project, or if necessary, by drawing on the agreed conflict resolution mechanisms.

f) Reimagine professional development for adaptation researchers: While the above strategies are focused on practical steps that can be taken as part of the participatory research process, the challenges and risks can also be reduced and managed by reimagining professional development for adaptation researchers. For example, as highlighted in Section 3.2.3, the range of skills and experiences required to navigate and negotiate complex participatory processes are not taught as part of traditional academic training programs (Cvitanovic et al. 2015b). While academics in the social sciences are more likely to receive training in the participatory skills outlined above, training programs for natural and physical scientists to engage outside of academia are typically focused on improving one-way communication skills - opposed to those associated with active listening, mediation, brokering, facilitation and translation that underpin successful collaboration among diverse individuals/groups separated by epistemological perspectives (Addison et al. 2013, Bernstein et al. 2017; Bednarek et al. 2018). Thus, institutional innovation and structural changes with the academic system to support the development of these skills in adaptation scientists, and particularly with early career adaptation scientists, are needed (Lang et al. 2012).

This type of institutional innovation will not occur in a vacuum, but can build on recent advances in the past decades that promote transdisciplinary and participatory research. For example, there is an improved collaboration across disciplines and between science and society (Fischer et al. 2015). Funders are increasingly, albeit slowly, supporting participatory research and rewarding stakeholder engagement and practical impact. While these are still marginal trends, they are seeds of change that can stimulate broader transformation in the design of current research strategies and incentive systems that primarily reward disciplinary science that does not engage with society. 
g) Ensure appropriate institutional support: Finally, the challenges and risks associated with participatory adaptation research can be managed and reduced by ensuring that appropriate and sufficient institutional supports are in place to protect both researchers and decision-makers. For example, participants of participatory research approaches should have access to formal legal and financial advice throughout the process of contract development to ensure that mechanisms are in place to protect their reputation, credibility and intellectual property. For example, prior to the commencement of research activity, contracts should be developed that clearly stipulate the conditions of the collaboration/partnership (e.g. the right to publish research outputs, the right to withdraw from the partnership should any conditions be not met, agreed upon conflict resolution measures, etc.) in order to protect the reputation and intellectual property of all participating individuals as well as their institutions.

Institutions should also explicitly recognise the additional challenges involved in implementing participatory research approaches, and ensure mechanisms are in place to support their staff should challenges arise, for example, via the establishment of formal mentoring programs. Finally, in light of the challenges and risks outlined above, and the time/resources needed to navigate them successfully so that desired outcomes can be realised, institutions (and particularly research institutions) should encourage good research practice by clearly defining and resourcing stakeholder engagement expectations (Cvitanovic et al. 2015b). This should include incentivising this type of research through the establishment of adequate metrics of science impact that account for the full suite of responsibilities researchers have within participatory research approaches, so as to underpin promotions and career progression (Keeler et al. 2017)

Table 1: Summary of the seven strategies that can be used to manage the challenges and risks of participatory adaptation research.

Participatory research risk management strategy
Insights for implementing participatory research risk management strategy 


\begin{tabular}{|c|c|}
\hline Choose participants carefully & $\begin{array}{l}\text { - Include participants who are open and respectful to } \\
\text { the perspectives and worldviews of others. } \\
\text { Ensure that the group is context specific, with balanced } \\
\text { representation of all relevant stakeholder groups. }\end{array}$ \\
\hline Monitor team composition & $\begin{array}{l}\text { Monitor team composition over time to identify (and } \\
\text { rectify) sources of conflict and/or power imbalances. } \\
\text { - Undertake regular (e.g. annual) stakeholder mapping } \\
\text { to ensure that team members are 'representative' of } \\
\text { all relevant groups across life of project. }\end{array}$ \\
\hline Set clear expectations & $\begin{array}{l}\text { - At the onset, jointly set agreed expectations for both } \\
\text { the research process and individual behaviours of } \\
\text { participants within the process. } \\
\text { Also at the onset of the research activity, identify and } \\
\text { agree on a range of internal and external conflict } \\
\text { resolution mechanisms should conflict arise. }\end{array}$ \\
\hline $\begin{array}{l}\text { Use different modes of scientific } \\
\text { inquiry }\end{array}$ & $\begin{array}{l}\text { Where appropriate, use reflexive and interpretive } \\
\text { modes of enquiry that directly consider and account } \\
\text { for the tensions between different viewpoints. } \\
\text { Use independent facilitation where possible to avoid } \\
\text { the overemphasis of a single perspective or knowledge } \\
\text { base dominating group discussions. }\end{array}$ \\
\hline $\begin{array}{l}\text { Incorporate mechanisms for } \\
\text { independent review }\end{array}$ & $\begin{array}{l}\text { Plan (and ensure budget) for independent reviews } \\
\text { throughout the entire research process. } \\
\text { Ensure reviews focus on both the overall functioning } \\
\text { and dynamics of the team and various participants, as } \\
\text { well as research outputs. } \\
\text { - Where possible (e.g. within budgetary constraints), } \\
\text { include independent reviews from multiple } \\
\text { peoples/groups. } \\
\text { Ensure reviews have a strong understanding of the } \\
\text { processes and practices of participatory research. }\end{array}$ \\
\hline $\begin{array}{l}\text { Reimagine professional } \\
\text { development }\end{array}$ & $\begin{array}{l}\text { Research institutions should provide training and } \\
\text { capacity develop for adaptation researchers in the full } \\
\text { suite of skills required by participatory research, such } \\
\text { as those associated with active listening, mediation, } \\
\text { brokering, facilitation and translation. }\end{array}$ \\
\hline $\begin{array}{l}\text { Ensure appropriate institutional } \\
\text { support }\end{array}$ & $\begin{array}{l}\text { - Ensure adequate and expert legal and financial support } \\
\text { is available to participants during the development of } \\
\text { participatory research contracts. } \\
\text { - Research institutions should encourage good research } \\
\text { practice by clearly defining stakeholder engagement } \\
\text { expectations. } \\
\text { - Research institutions should recognise and reward the } \\
\text { full suite of responsibilities researchers have within } \\
\text { participatory research approaches. }\end{array}$ \\
\hline
\end{tabular}


836 Calls for the implementation of participatory research approaches have become commonplace in the pursuit of generating usable climate adaptation science that will be beneficially incorporated into decision-making processes. However, despite the many benefits of such research approaches, as we have highlighted through this review, their implementation also poses additional challenges for participants, in some cases with subsequent risks at personal, professional or institutional levels. These challenges, however, are not insurmountable, and in this paper we have drawn upon other sectors and disciplines where participatory research approaches are commonly implemented to start to identify strategies for managing these challenges, and reduce the risks they pose (outlined in Table 1). Underpinning all strategies is the central importance of relationships, trust, credibility and social learning, as researchers, practitioners, policy-makers and the broader community embark together on this new journey toward participatory knowledge generation and use. While the implementation of these strategies will need to be adapted to fit within specific contexts and processes, being mindful of the challenges associated with participation, and ways to manage them, will help enhance the benefits conferred through participatory research processes.

\section{Acknowledgements}

854 We thank Justine Lacey for insightful comments and discussions that greatly improved this manuscript. Financial support was provided by the Centre for Marine Socioecology at the University of Tasmania, Australia. PFEA is supported by the Natural Environment Research Council [NE/N005457/1]. We also thank the two anonymous reviewers who provided constructive comments that helped improve this manuscript.

\section{References}

Addison PFE, Rumpff L, Bau SS, Carey JM, Chee YE, Jarrad FC, McBride MF, Burgman MA (2013) Practical solutions for making models indispensable in conservation decisionmaking. Diversity and Distributions 19, 490-502.

Adger WN, Huq S, Brown K, Conway D, Hulme M (2003) Adaptation to climate change in the 865 developing world. Progress in Development Studies 3, 179-195. 
Adger WN, Arnell NW, Tompkins EL (2005) Successful adaptation to climate change across scales. Global Environmental Change 15, 77-86.

Alston LJ, Libecap G, Mueller B (1999) Titles, conflicts and land use: The development of property rights and land reform on the Brazilian frontier. University of Michigan Press, USA.

Arnstein S (1969) A Ladder of Citizen Participation. Journal of the American Institute of Planners 35 (4), 216-224.

Austin DE (2004) Partnerships, not projects! Improving the environment through collaborative research and action. Human Organizations 63, 419-430.

Balvanera P, Daw TM, Gardner TA, Martin-López B, Norström AV, Speranza Cl, Spierenburg M, Bennett EM, Farfan M, Hamann M, Kittinger JN, Luthe T, Maass M, Peterson GD, Perez-Verdin G (2017) Key features for more successful place-based sustainability research on social-ecological systems: a Programme on Ecosystem Change and Society (PECS) perspective. Ecology and Society 22(1), 14.

Bednarek A, Wyborn C, Cvitanovic C, Meyer R, Colvin R, Addison PFE, Close SL, Curran K, Farooque M, Goldman E, Hart D, Mannix H, McGreavy B, Parris A, Posner S, Robinson C, Ryan M, Leith P (2018) Boundary-spanning at the science-policy interface: The practitioners' perspective. Sustainability Science 13, 1175-1183.

Beier P, Hansen LJ, Helbrecht L, Behar D (2016) A how-to guide for coproduction of actionable science. Conservation Letters 10, 288-296.

Bernsten MJ, Reifscheider K, Bennett I, Wetmore JM (2017) Science Outside the Lab: Helping graduate students in science and engineering understand the complexities of science policy. Science and Engineering Ethics 23, 861-882.

Birner R, Wittmer H (2004) On the 'efficient boundaries of the state': the contribution of transaction-cost economics to the analysis of decentralization and devolution in naturel resource management. Environment and Planning C: Politics and Space 22, 667-685.

Blythe J, Nash K, Yates J, Cumming G (2017) Feedbacks as a bridging concept for advancing transdisciplinary sustainability research. Current Opinion in Environmental Sustainability 26, 114-119.

Bodin O, Crona BI (2009) The role of social networks in natural resource governance: what relational patterns make a difference. Global Environmental Change 19, 366-374.

Boillat S, Berkes F (2013) Perception and interpretation of climate change among Quechua Farmers of Bolivia: Indigenous Knowledge as a resource for adaptive capacity. Ecology and Society 18(4), 21. 
Bornmann L, Haunschild R, Marx W (2016) Policy documents as sources for measuring societal impact: how often is climate change research mentioned in policy-related documents? Scientometrics 109,1477-1495.

Boykoff MT (2007) From convergence to contention: United States mass media representations of anthropogenic climate change science. Transactions of the Institute of British Geographers 32, 477-489.

Bremer S, Meisch S (2017) Co-production in climate change research: reviewing different perspectives. WIRES Climate Change. DOI: 10.1002/wcc.482.

Bromham L, Dinnage R, Hua X (2016) Interdisciplinary research has consistently lower funding success. Nature 534, 684-687.

Brown LD, Tandon R (1983) Ideology ad political economy in inquiry: action research and participatory research. Journal of Applied Behavioural Science 19, 277-294.

Butler JRA, Suadnya W, Puspadi K, Sutaryono Y, Wise RM, Skewes TD, Kirono D, Bohensky EL, Handayani T, Habibi P, Kisman M, Suharto I, Hanartani, Supartarningsih S, Ripaldi A, Fachry A, Yanuartati Y, Abbas G, Duggan K, Ash A (2014) Framing the application of adaptation pathways for rural livelihoods and global change in eastern Indonesian islands. Global Environmental Change 28, 368-382.

Campbell LM (2005) Overcoming Obstacles to Interdisciplinary Research. Conservation Biology 19, 574-577.

Campos-Arceiz A, Pin Koh L, Primack RB (2013) Are conservation biologists working too hard? Biological Conservation 166, 186-190.

Cash DW, Borck JC, Patt AG (2006) Countering the loading-dock approach to linking science and decision making - Comparatice analysis of El Nino/Southern Oscillation (ENSO) forecasting systems. Science, Technology and Human Values 31, 465-494.

Cash D, Buizer J (2005) Knowledge-action systems for seasonal to interannual climate forecasting: Summary of a workshop. The National Academies Press, Washington, DC, USA.

Cash DW, Clark WC, Alcock F, Dickson NM, Eckley N, Guston DH, Jager J, Mitchell RB (2003) Knowledge systems for sustainable development. Proceedings of the national Academy of Science 100, 8086-8091.

Cash DW, Moser SC (2000) Linking global and local scales: designing dynamic assessment and management processes. Global Environmental Change 10, 109-120.

Cheruvelil KS, Soranno PA, Weathers KC, Hanson PC, Goring SJ, Filstrup CT, et al. (2014) Creating and maintaining high-performing collaborative research teams: the importance of diversity and interpersonal skills. Frontiers in Ecology and the Environment 12, 31-38. 
Cook CN, Mascia MB, Schwartz MW, Possingham HP, Fuller RA (2013) Achieving conservation science the bridges the knowledge-action boundary. Conservation Biology 27, 669-678.

Colvin RM, Witt GB, Lacey J (2015) The social identity approach to understanding sociopolitical conflict in environmental and natural resources management. Global Environmental Change 34, 237-246.

Colvin RM, Witt GB, Lacey J (2016) Approaches to identifying stakeholders in environmental management: Insights from practitioners to go beyond the 'usual suspects'. Land Use Policy 52, 266-276.

Cornell S, Berkhout F, Tuinstra W, Tàbara JD, Jäger J, Chabay I, de Wit B, Langlais R, Mills D, Moll P, Otto IM, Petersen A, Pohl C, van Kerkhoff L (2013) Opening up knowledge systems for better responses to global environmental change. Environmental Science and Policy 28: 60-70.

Cornwall A, Jewkes R (1995) What is Participatory Research? Social Science and Medicine 41 (12):1667-1676.

Crona BI, Bodin O (2006) What you know is who you know? Communication patters among resource extractors as a pre-requisite for co-management. Ecology ad Society 11, 7.

Cvitanovic C, Marshall N, Wilson SK, Dobbs K, Hobday A (2014a) Perceptions of Australian marine protected managers regarding the role, importance, and achievability of adaptation for managing the risks of climate change . Ecology and Society 19(4), 33.

Cvitanovic C, Fulton CJ, Wilson SK, van Kerkhoff L, Cripps IL, Muthiga N (2014b) Utility of primary scientific literature to environmental managers: An international case study on coral-dominated marine protected areas. Ocean and Coastal Management 102, 7278.

Cvitanovic C, Hobday AJ, van Kerkhoff L, Wilson SK, Dobbs K, Marshall NA (2015a) Improving knowledge exchange among scientists and decision-makers to facilitate the adaptive governance of marine resources: a review of knowledge and research needs. Ocean and Coastal Management 112, 25-35.

Cvitanovic C, Hobday AJ, van Kerkhoff L, Marshall NA (2015b) Overcoming barriers to knowledge for adaptive resource management; the perspectives of Australian marine scientists. Marine Policy 52, 38-44.

Cvitanovic C, McDonald J, Hobday AJ (2016) From science to action: Principles for undertaking environmental research that enables knowledge exchange and evidencebased decision-making. Journal of Environmental Management 183, 864-874.

Cvitanovic C, Cunningham R, Dowd AM, Howden SM, van Putten El (2017) Using social network analysis to monitor and assess the effectiveness of knowledge brokers at connecting scientists and decision-makers: As Australian case study. Environmental Policy and Governance DOI: 10.1002/eet.1752. 
Deelstra Y, Nooteboom SG, Kohlmann HR, van den Berg J, Innanen S (2003) Using knowledge for decision-making purpose in the context of large projects in the Netherlands. Environmental Impact Assessment Review 23, 517-541.

Djenontin INS, Meadow AM (2018) The Art of Co-production of Knowledge in Environmental Sciences and Management: Lessons from International Practice. Environmental Management 61, 885-903.

Dilling L, Lemos MC (2011) Creating usable science: opportunities and constraints for climate knowledge use and their implications for science policy. Global Environmental Change 21, 680-689.

Doubleday R, Wilsdon J (2012) Science policy: Beyond the great and good. Nature 485, 301302.

Eckley N (2002) Dependable dynamism lessons for designing scientific assessment processes in consensus negotiations. Global Environmental Change 12, 15-23.

Eckley N, Clark W, Farrell A, Jäger J, Stanners D (2001) Designing effective assessments: The role of participation, science and governance, and focus. EEA, Copenhagen, Denmark.

Emanuel EJ, Wendler D, Grady C (2000) What makes clinical research ethical? Journal of the American Medical Association 283, 2701-2711.

Evans MC, Cvitanovic C (2018) An introduction to achieving policy impact for early career researchers. Palgrave Communications, DOI: 10.1057/s41599-018-0144-2.

Evans MC, Davila F, Toomey A, Wyborn C (2017) Embrace complexity to improve conservation decision making. Nature Ecology \& Evolution, doi:10.1038/s41559-0170345-x.

Farrell AE, Jäger J (2005) Assessments of regional and global environmental risks: Designing processes for the effective use of science in decision-making. RFF Press, Washington, USA.

Fazey I, Fischer J, Lindenmayer DB (2005) What do conservation biologist publish? Biological Conservation 124, 63-73.

Fazey I, Fazey JA, Salisbury JG, Lindenmayer DB, Dovers S (2006) The nature and role of experiential knowledge for environmental conservation. Environmental Conservation 33(1),1-10.

Fazey I, Fazey JA, Fischer J, Sherren K, Warren J, Noss RF, Dovers SR (2007) Adaptive capacity and learning to learn as leverage for social-ecological resilience. Frontiers in Ecology and Environment 5, 375-380.

Fazey I, Schäpke N, Caniglia G, Patterson J, Hultman J, Van Mierlo B, Säwe F, Wiek A, Wittmayer JM, Aldunce P, Al Waer H, Battacharya N, Bradbury H, Carmen E, Colvin J, Cvitanovic C, D'Souza, M, Gopel M, Goldstein B, Hämäläinen T, Harper G, Henfry T, Hodgson A, Howden MS, Kerr A, Klaes M, Lyon C, Midgley G, Moser S, Mukherjee N, 
Müller K, O'Brien K, O'Connell DA, Olsson P, Page G, Reed MS, Searle B, Silvestri G, Spaiser V, Strasser T, Tschakert P, Uribe-Calvo N, Waddell S, Rao-William J, Wise R, Wolstenholme R, Woods M, Wyborn C (2018) Ten essentials for action-oriented and second order energy transitions, transformations and climate change research. Energy Research \& Social Science, Vol 40: 54-70.

Few R (2001) Containment and counter-containment: planner/community relations in conservation planning. The Geographical Journal 167, 111-124.

Few R (2003) Participation or containment? Insights from the planning of protected areas in Belize', in: J. Pugh, R.B. Potter (eds), Participatory Planning in the Caribbean: Lessons from Practice, Ashgate, Aldershot, UK, 23-44.

Few R, Brown K, Tompkins EL (2007) Public participation and climate change adaptation: avoiding the illusion of inclusion. Climate Policy 7, 46-59.

Fielding KS, Hornsey MJ (2016) A social identify analysis of climate change and environmental attitudes and behaviours: Insights and opportunities. Frontiers in Psychology 7, 121.

Fischer J, Gardner TA, Bennett EM, Balvanera P, Biggs R, Carpenter S, Daw T, Folke C, Hill R, Hughes TP, Luthe T, Maass M, Meacham M, Norström A V, Peterson G, Queiroz C, Seppelt R, Spierenburg M, Tenhunen J (2015) Advancing sustainability through mainstreaming a social-ecological systems perspective. Current Opinions in Environmental Sustainability 14, 144-149.

Frusher SD, Hobday AJ, Jennings SM, Creighton C, D'Silva D, Haward M, Holbrook NJ, Nursey-Bray M, Pecl GT, van Putten El (2014) The short history of research in a marine climate change hotspot: from anecdote to adaptation in south-east Australia. Reviews in Fish Biology and Fisheries 24, 593-611.

Gaziulusoy Al, Ryan C, McGrail S, Chandler P, Twomey P (2016) Identifying and addressing challenges faced by transdisciplinary research teams in climate change research. Journal of Cleaner Production 123, 55-64.

Gearheard S, Pocernich M, Stewart R, Sanguya J, Huntington HP (2010) Linking Inuit knowledge and meteorological station observations to understand changing wind patterns at Clyde River, Nunavut. Climate Change 100, 267-294.

Grant J, Nelson G, Mitchell T (2008) Negotiating the challenges of participatory action research: Relationships, power, participation, change and credibility. The SAGE Handbook of Action Research, P. Reason and H. Bradbury (Eds), SAGE Publications Ltd.

Green LW, Glasgow RE, Atkins D, Stange K (2009) Making evidence from research more relevant, useful, and actionable in policy, program planning and practice slips "twixt cup and lip". American Journal of Preventative Medicine 37, S187-S191. 
Greenwood DJ, Levin M (2007) Introduction to action research: Social research for social change. Second Edition, Sage Publications Ltd.

Grose MR, Brown JN, Narse S, Brown JR, Murphy BF, Langlais C, Gupta AS, Moise AF, Irving DB (2014) Assessment of the CMIP5 global climate model simulations of the western tropical Pacific climate system and comparison to CMIP3. International Journal of Climatology 34, 3382-3399.

Gupta J (2016) Climate change governance: history, future, and triple-loop learning. WIREs Climate Change 7, 192-210.

Guston DH (2001) Boundary organizations in environmental policy and science: An introduction. Science, Technology and Human Values 26, 339-408.

Haslam SA, Eggins RA, Reynolds KJ (2003) The ASPIRe model: Actualizing social and personal identify resources to enhance organizational outcomes. Journal of Occupational and Organizational Psychology 76, 83-113.

Haasnoot M, Kwakkel FH, Walker WE, ter Maat J (2013) Dynamic adaptive policy pathways: A method for crafting robust decisions for a deeply uncertain world. Global Environmental Change 23, 485-498.

Harris F, Lyon F (2014) Transdisciplinary environmental research: a review of approaches to knowledge co-production. Nexus Network Think Piece Series, Paper, 2.

Hegger D, Dieperink C (2014) Toward successful joint knowledge production for climate change adaptation: lessons from six regional projects in the Netherlands. Ecology and Society, 19(2), 34.

Hemming C, Burgman MA, Haneea AM, McBride MF, Wintle BC (2017) A practical guide to structured expert elicitation using the IDEA protocol. Methods in Ecology and Evolution 9, 169-180.

Hewitson BC, Daron J, Crane RG, Zermoglio MF, Jack C (2014) Interrogating empiricalstatistical downscaling. Climatic Change 122, 539-554.

Hoeft TJ, Burke W, Hopkins SE, Charles W, Trinidad SB, James RD, Boyer BB (2014) Building partnerships in community-based participatory research: Budgetary and other cost considerations. Health Promotion Practice 15, 263-270.

Howden SM, Soussana JF, Tubiello FN, Chhetri N, Dunlop M, Meinke H (2007) Adapting agriculture to climate change. Proceedings of the National Academy of Sciences of the United States of America 104, 19691-19696.

Howden SM, Schtoeter S, Crimp S, Hanigan I (2014) The changing roles of science in managing Australian droughts: An agricultural perspective. Weather and Climate Extremes 3, 80-89. 
Huntjens P, Eshuis J, Termeer C, van Buuren A (2014) Forms and foundations of action research. Action Research for Climate Change Adaptation: Developing and Applying Knowledge for Governance, A. van Buuren, and M. van Vliet, Eds., Routledge.

IPCC (2014) Climate Change 2014: Impacts, Adaptation, and Vulnerability. Part A: Global and Sectoral Aspects. Contribution of Working Group II to the Fifth Assessment Report of the Intergovernmental Panel on Climate Change [Field, C.B., V.R. Barros, D.J. Dokken, K.J. Mach, M.D. Mastrandrea, T.E. Bilir, M. Chatterjee, K.L. Ebi, Y.O. Estrada, R.C. Genova, B. Girma, E.S. Kissel, A.N. Levy, S. MacCracken, P.R. Mastrandrea, and L.L.White (eds.)]. Cambridge University Press, Cambridge, United Kingdom and New York, NY, USA, 1132 pp.

IPCC, 2018: Summary for Policymakers. In: Global warming of $1.5^{\circ} \mathrm{C}$. An IPCC Special Report on the impacts of global warming of $1.5^{\circ} \mathrm{C}$ above pre-industrial levels and related global greenhouse gas emission pathways, in the context of strengthening the global response to the threat of climate change, sustainable development, and efforts to eradicate poverty [V. Masson-Delmotte, P. Zhai, H. O. Pörtner, D. Roberts, J. Skea, P.R. Shukla, A. Pirani, W. Moufouma-Okia, C. Péan, R. Pidcock, S. Connors, J. B. R. Matthews, Y. Chen, X. Zhou, M. I. Gomis, E. Lonnoy, T. Maycock, M. Tignor, T. Waterfield (eds.)]. World Meteorological Organization, Geneva, Switzerland, 32 pp.

Jacobs K (2014) Lessons from the National Climate Assessment on science translation and boundary organizations. US Clivar Variations 12 (4), 1-4.

Jacobson N, Butterill D, Goering P (2004) Organizational factors the influence universitybased researchers' engagement in knowledge transfer activities. Science Communication 25, 246-259.

Jasanoff S (2004) States of knowledge: the co-production of science and social order. Routledge, London, UK.

Kahan D (2010) Fixing the communications failure. Nature 463, 296-297.

Keeler BL, Chaplin-Kramer R, Guerry AD, Addison PFE, Bettigole C, Burke IC, Gentry B, Chambliss L, Young C, Travis AJ, Darimont ST, Gordon DR, Hellmann J, Kareiva P, Monfort S, Olander L, Profeta T, Possingham HP, Slotterback C, Sterling E, Ticktin T, Vira B (2017) Society is ready for a new kind of science - Is academia? Bioscience 67, 591-592.

Khanlou N, Peter E (2005) Participatory action research: considerations for ethical review. Social Science and Medicine 60, 2333-2340.

King TK, O'Meara D (2018) 'The people have spoken': how cultural narratives politically trumped the best available science (BAS) in managing the Port Phillip Bay fishery in Australia. Maritime Studies, doi.org/10.1007/s4015. 
Klenk N, Fiume A, Meehan K, Gibbes C (2017) Local knowledge in climate adaptation research: moving knowledge frameworks from extraction to co-production. Wiley Interdisciplinary Reviews: Climate Change 8(5), e475.

Kleppa E, Sanne B, Tell GS (2008) Working overtime is associated with anxiety and depression: the Hordaland Health Study. Journal of Occupational and Environmental Medicine 50, 658-666.

Lacey J, Howden SM, Cvitanovic C, Dowd AM (2015) Informed adaptation: Ethical considerations for adaptation researchers and decision-makers. Global Environmental Change 32, 200-210.

Lacey J, Howden M, Cvitanovic C, Colvin RM (2018) Understanding and managing trust at the climate science-policy interface. Nature Climate Change 8, 22-28.

Lang DJ, Wiek A, Bergmann M, Stauffacher M, Martens P, Moll P, Swilling M, Thomas CJ (2012) Transdisciplinary research in sustainability science: practice, principles and challenges. Sustainability Science 7, 25-43.

Lemos MC, Arnott JC, Ardoin NM, Baja K, Bednarek AT, Dewulf A, Fieseler C, Goodrich KA, Jagannathan K, Klenk K, MachKJ, Meadow AM, Meyer R, Moss R, Nichols L, Sjostrom D, Stults M, Turnhout E, Vaughan C, Wong-Parodi G, Wyborn C (2018) To co-produce or not to co-produce. Nature Sustainability 1, 722-724.

Lewin K (1946) Action research and minority problems. Journal of Social Issues 46, 34-46.

Linklater WL (2003) Science and management in a conservation crisis: A case study with rhinoceros. Conservation Biology 17, 968-975.

Lubchenco J (1998) Entering the century of the environment: a new social contract for science. Science $279,491-497$.

Mackewn J (2008) Facilitation as Action Research in the Moment. The SAGE Handbook of Action Research, P. Reason, and H. Bradbury, Eds., SAGE Publications Ltd.

Margerum RD (2002) Evaluating Collaborative Planning: Implications from an Empirical Analysis of Growth Management. Journal of the American Planning Association 68, 179-193.

Martin TG, Burgman MA, Fidler F, Kuhnert PM, Low-Choy S, McBride M, Mengersen K (2012) Eliciting expert knowledge in Conservation Science. Conservation Biology 26, 29-38.

Mauser W, Klepper G, Rice M, Schmalzbauer BS, Hackmann H, Leemand R, Moore H (2013) Transdisciplinary global change research: the co-creation of knowledge for sustainability. Current Opinions in Environmental Sustainability 5, 420-431. 
Meadow AM, Ferguson DB, Guido Z, Horangic A, Owen G (2015) Moving toward the deliberate co-production of climate science knowledge. Weather, Climate and Society 7, 179-191.

Meinke H, Howden SM, Struik PC, Nelson R, Rodriguez D, Chapman SC (2009) Adaptation science for agriculture and natural resource management- urgency and theoretical basis. Current Opinions in Environmental Sustainability 1, 69-76.

Meyer M (2010) The rise of the knowledge broker. Science Communication 32, 118-127.

Millar RJ, Fuglestvedt JS, Friedlingstein P, Rogelj J, Grubb MJ, Matthews HD, Skeie RB, Forster PM, Frame DJ, Allen MR (2017) Emission budgets and pathways consistent with limting warming to $1.5^{\circ} \mathrm{C}$. Nature Geoscience $10,741-747$.

Mols F, Haslam SA, Jetten J, Steffens NK (2014) Why a nudge is not enough: A social identify critique of governance by stealth. European Journal of Political Research 54, 81-98.

Naess LO (2012) The role of local knowledge in adaptation to climate change. WIREs Climate Change 4, 99-106.

Newig J, Günther D, Pahl-Wostl C (2010) Synapses in the network: learning in governance in the context of environmental management. Ecology and Society 15(4), 24.

Nicholls RJ, Cazenave A (2010) Sea-level rise and its impact on coastal zones. Science 328, 1517-15-20.

O'Leary BC, Kvist K, Bayliss HR, Derroire G, Healey JR, Hughes K, Kleinschroth F, Sciberras M, Woodcock P, Pullin AS (2016) The reliability of evidence review methodology in environmental science and communication. Environmental Science and Policy 64, 7582.

Park P, Brydon-Miller M, Hall B, Jackson T (1993) (Eds) Voices of change: participatory research in the United States and Canada. Ontario Institute for Studies in Education Press, Toronto, Canada.

Parrott L, Meyer WS (2012) Future landscape: managing within complexity. Frontiers in Ecology and Environment 10, 382-389.

Pecl GT, Araújo MB, Bell JD, Blanchard J, Bonebrake TC, Chen IC, Clark TD, Colwell RK, Danielsen F, Evengård B, Falconi L, Ferrier S, Frusher S, Garcia RA, Griffis RB, Hobday AJ, Janion-Scheepers C, Jarzyna MA, Jennings S, Lenoir J, Linnetved HI, Martin VY, McCormack PC, McDonald J, Mitchell NJ, Mustonen T, Pandolfi JM, Pettorelli N, Popova E, Robinson SA, Scheffers BR, Shaw JD, Sorte CJB, Strugnell JM, Sunday JM, Tuanma MN, Vergés A, Villanueva C, Wernberg T, Wapstra E, Williams SE (2017) Biodiversity redistribution under climate change: Impacts on ecosystems and human well-being. Science 355, DOI: 10.1126/science.aai9214 
Picketts IM (2018) The best laid plans: Impacts of politics on local climate change adaptation. Environmental Science and Policy 87, 26-32.

Pielke Jr RA (2007) The honest broker: Making sense of science in policy and politics. Cambridge, Cambridge University Press.

Polanyi M, Cockburn L (2003) Opportunities and Pitfalls of Community-Based Research: A Case Study. Michigan Journal of Community Service Learning, Spring, 16-25.

Polk M (2015) Transdisciplinary co-production: Designing and testing a transdisciplinary research framework for societal problem solving. Futures 65, 110-122.

Rafols I, Leydesdorff L, O'Hare A, Nightingale P, Stirling A (2012) How journal rankings can suppress interdisciplinary research: A comparison between Innovation Studies and Business \& Management. Research Policy 41, 1262-1282.

Ramirez-Villegas J, Challinor AJ, Thornton PK, Jarvis A (2013) Implications of regional improvement in global climate models for agriculture impact research. Environmental Research Letters 8, 024018.

Reason P, Bradbury H (Eds.) (2008a) The SAGE Handbook of Action Research. SAGE Publications Ltd.

Reason P, Bradbury H (Eds.) (2008b) Introduction. The SAGE Handbook of Action Research, P. Reason, and H. Bradbury, Eds., SAGE Publications, 1-10.

Reed MS (2008) Stakeholder participation for environmental management: a literature review. Biological Conservation 141, 2417-2431.

Reed MS (2016) The Research Impact Handbook. Fast Track Impact Pty Ltd, Aberdeenshire, UK.

Reed MS, Stringer LC, Fazey I, Evely AC, Kruijsen JHJ (2014) Five principles for the practice of knowledge exchange in environmental management. Journal of Environmental Management 146, 337-345.

Reed MS, Vella S, Challies E, de Vente J, Frewer L, Hohenwallner-Ries D, Huber T, Neumann RK, Oughton EA, del Ceno JS, van Delden H (2017) A theory of participation: what makes stakeholder and public engagement in environmental management work. Restoration Ecology 26, S7-S17.

Reevy, GM \& Deason, G (2014) Predictors Of Depression, Stress, And Anxiety Among NonTenure Track Faculty. Frontiers In Psychology 5, DOI: 10.3389/fpsyg.2014.00701.

Reid H, Alam M, Berger R, Cannon T, Huq S, Milligan A eds (2009) Community-based adaptation to climate change, participatory learning and action 60. IIED, London, UK. 
Reinecke $S$ (2015) Knowledge brokerage designs and practices in four European climate services: A role model for biodiversity hotspots? Environmental Science and Policy 54, 513-521.

Runhaar H, Wilk B, Persson Å, Uittenbroek C, Wamsler C (2018) Mainstreaming climate adaptation: taking stock about "what works" from empirical research worldwide. Regional Environmental Change 18, 1201-1210.

Salter J, Robinson J, Wiek A (2010) Participatory methods of integrated assessment - A review. WIREs Climate Change 1, 697-717.

Sardar Z (2010) Welcome to postnormnal times. Futures 42, 435-444.

Sarkki S, Niemela J, Tinch R, Van den Hove S, Watt A, Young J (2014) Balancing credibility, relevance and legitimacy: A critical assessment of trade-offs in science-policy interfaces. Science and Public Policy 41, 194-206.

Schensul SL, Schensul JJ, Singer M, Weeks M, Brault M (2014) Participatory Methods and Community-Based Collaborations. Handbook of Methods in Cultural Anthropology, 2 ed., H. R. Bernard, and C. C. Gravlee, Eds., Rowman \& Littlefield Publishers, 178-204.

Schulz AJ, Israel BA, Lantz P (2003) Instrument for evaluating dimensions of group dynamics within community-based participatory research partnerships. Evaluation and Program Planning 26 (3), 249-262.

Slovic, P (1987) Perception of Risk. Science 236, 280-285.Supran G, Oreskes N (2017) Assessing ExxonMobil's climate change communications (1977-2014). Environmental Research Letters 12, 084019.

Tai APK, Val Martin M, Heald CL (2014) Threat to future global food security from climate change and ozone air pollution. Nature Climate Change 4, 817-821.

Tax S (1958) The Fox Project. Human Organization 17, 17-19.

Tengö M, Hill R, Malmer P, Raymond CM, Spierenburg M, Danielson F, Elmqvist T, Folke C (2017). Weaving knowledge systems in IPBES, CBD and beyond - lessons learned for sustainability. Current Opinions in Environmental Sustainability 26-27, 17-25.

Timmings C, Khan S, Moore JE, Marquez C, Pyka K, Straus SE (2016) Ready, Set, Change! Development and usability testing of an online readiness for change decision support tool for healthcare organizations. BMC Medical Informatics and Decision Making 16, 24.

Trimble M, Lázaro M (2014) Evaluation Criteria for Participatory Research: Insights from Coastal Uruguay. Environmental Management 54, 122-137.

Van Kerkhoff L, Lebel L (2015) Coproductive capacities: rethinking science-governance relations in a diverse world. Ecology and Society 20(1), 14. 
281

Van Kerkhoff L, Pilbeam (2017) Understanding socio-cultural dimensions of environmental decision-making: A knowledge governance approach. Environmental Science and Policy 73, 29-37.

Virtanen M, Ferrie JE, Singh-Manoux A, Shipley MJ, Stansfeld SA, Marmot MG, Ahola K, Vahtera J, Kivimäki M (2011) Long working hours and symptons of anziety and depression: a 5-year follow-up of the Whitehall II study. Psychological Medicine 41, 5485-2494.

Wallerstein NB, Duran B (2008) The Theoretical, Historical, and Practice Roots of CBPR. Community-Based Participatory Research for Health: From Process to Outcomes, M. Minkler, and N. B. Wallerstein, Eds., John Wiley \& Sons, 25-46.

Watermeyer R, Hedgecoe A (2016) Selling 'impact': peer reviewer projections of what is needed and what counts in REF impact case studies. A retrospective analysis. Journal of Education Policy 31, 651-665.

Wheeler T, von Braun J (2013) Climate change impacts on global food security. Science 341, 508-513.

Wiber M, Berkes F, Charles A, Kearney J (2004) Participatory research supporting community-based fishery management. Marine Policy 28, 459-468.

Wiek A, Withycombe L, Redman CL (2011) Key competencies in sustainability: a reference framework for academic program development. Sustainability Science 6, 203-218.

Wise RM, Fazey I, Stafford Smith M, Park SE, Eakin HC, Archer Van Garderen ERM, Campbell B (2014) Reconceptualising adaptation to climate change as part of pathways of change and response. Global Environmental Change 28, 325-336.

Wyborn CA (2015) Connecting knowledge with actions through coproductive capacities: adaptive governance and connectivity conservation. Ecology and Society 20(1), 11. 
Highlights:

- Participatory research approaches are increasingly advocated as an effective means to produce usable climate adaptation science.

- Despite increased advocacy for the implementation of participatory research approaches, our understanding has remained largely uncritical.

- We review the literature on participatory research in climate adaptation science to identify potential challenges and risks.

- We also outline seven strategies for how to manage these challenges and risks and maximise the potential for success. 


\title{
Maximising the benefits of participatory climate adaptation research by understanding and managing the associated challenges and risks
}

\author{
Christopher Cvitanovic ${ }^{1,2^{*}}$, Mark Howden ${ }^{3}$, R.M. Colvin ${ }^{3}$, Albert Norström ${ }^{4}$, Alison M. \\ Meadow $^{5}$, P.F.E Addison ${ }^{6}$
}

\footnotetext{
${ }^{1}$ Australian National Centre for the Public Awareness of Science, Australian National
} University, Canberra, Australia.

${ }^{2}$ Centre for Marine Socioecology, University of Tasmania, Australia.

${ }^{3}$ Climate Change Institute, Australian National University, Canberra, Australia.

${ }^{4}$ Stockholm Resilience Centre, Stockholm University, Sweden.

${ }^{5}$ Institute of the Environment, University of Arizona, Tucson, AZ, US.

${ }^{6}$ Interdisciplinary Centre for Conservation Science, Department of Zoology, University of Oxford, UK, OX1 $3 S Z$.

* Communicating author: Christopher Cvitanovic Telephone: +61 404052278

Email: christopher.cvitanovic@anu.edu.au

\section{Abstract}

4 Participatory research approaches are increasingly advocated as an effective means to 5 produce usable climate adaptation science, and increase the likelihood that it will be beneficially incorporated into decision-making processes. However, while the implementation of participatory research approaches, such as those associated with knowledge co-production, have become increasingly commonplace, to date there has been little consideration given to the challenges and subsequent risks associated with their use. To start to address this gap we review the literature on participatory research in climate 
adaptation science. In doing so we identify and articulate several challenges, and subsequent risks, created by participatory research approaches to adaptation (i) science, (ii) scientists and scientific institutions, (iii) decision-makers and decision-making institutions and (iv) research funders. Based on this we identify seven strategies to help manage these challenges and reduce the associated risks: (a) choose participants carefully; (b) monitor team composition and adjust as necessary; (c) set clear expectations, and agreed conflict resolution mechanisms; (d) use different modes of scientific inquiry that can account for different knowledges and biases; (e) incorporate mechanisms for independent review at all stages of research; (f) reimagine professional development for adaptation researchers, and (g) ensure that appropriate institutional support is in place. These strategies can help to increase the likelihood that participatory research approaches will achieve their goal of generating knowledge that will help society successfully navigate modern day sustainability challenges, such as those posed by climate change.

Keywords: co-production, risk, adaptation science, adaptation scientists, decision-makers, research funders

\section{Introduction}

Anthropogenic climate change is widely considered to be one of the greatest threats facing humanity (e.g. Nicholls and Cazenave 2010; Wheeler and von Braun 2013; Tai et al. 2014; Pecl et al. 2017). Despite global efforts to ameliorate climate changes via the mitigation of greenhouse gases, historical and ongoing emissions mean that impacts from climate change are already occurring and further impacts are now unavoidable (Millar et al. 2017; IPCC 2018). As a result, adaptation has rapidly emerged as one of the biggest global agenda items of the 21st century to help safeguard human well-being and prosperity into the future (Adger et al. 2003; Howden et al. 2007; IPCC 2014).

The growing acknowledgement of the importance of adaptation to address climate variability and change has been accompanied by increasing research effort to support adaptation decision-making (Howden et al. 2014; Frusher et al. 2014). Commonly termed 'adaptation science' (sensu Meinke et al. 2009), much of this research has focused on 
identifying and assessing the threats, risks, uncertainties and opportunities associated with climate change, to generate the knowledge and insights required to effect change in socioecological systems that will increase their adaptive capacity and performance. This is typically achieved by analysing problems without a predefined disciplinary lens so as to allow for the inclusion of multiple perspectives and knowledge systems (scientific- , local- , cultural- , experiential-knowledge, etc.) to generate pathways to support decision-makers in navigating the full suite of socio-ecological complexities and uncertainties associated with adapting to climate change (Haasnoot et al. 2013; Butler et al. 2014; Wise et al. 2014).

Despite the applied nature of adaptation science, and a significant increase in its production over the past two decades, the uptake and integration of new adaptation knowledge into decision-making processes remains limited (e.g. Cvitanovic et al. 2014a; Runhaar et al. 2018). This may, in part, result from the key uncertainties associated with adaptation science, meaning a clear course of action is not necessarily evident to decision-makers. For example, the quantity of academic publications that purport to have decision-relevant insights is high, and includes overlap of topics and conflicting recommendations (O'Leary et al. 2016). Navigating this inefficiency is time-expensive and confusing for decision-makers. When a relevant study is identified, the difficulties continue as there are uncertainties in the global climate models on which adaptation options are premised (Ramirez-Villegas et al. 2013; Grose et al. 2014) and choosing downscaling methods and models that appropriately inform finer scale adaptation options is complex (Hewitson et al, 2014). This complexity is further compounded by the variation in how different researchers define and thus consider adaptation options, which may lead to researchers becoming advocates for their own work rather than promoting the broader array of adaptation options that are actually available (Lacey et al. 2015). Finally, a number of well documented structural impediments and barriers to knowledge exchange between adaptation scientists and decision-makers persist. This includes, but is not limited to, scientific content being 'locked' behind journal paywalls and the time lags between data collection and availability (Cvitanovic et al. 2015a). While such challenges are not unique to climate adaptation science (e.g. Evans et al. 2017), they represent significant barriers to the capacity for decision-makers to implement scienceinformed adaptation measures. 
As a means to produce more usable climate adaptation science (Dilling and Lemos 2011), and increase the likelihood that it will be beneficially incorporated into decision-making processes, there has been a trend towards the implementation of participatory research approaches for generating adaptation science (Meadow et al. 2015; Klenk et al. 2017). While the concept of participatory research can be defined in various ways, we use the term here to describe the process of securing the active involvement of a broad range of stakeholders such as policy-makers and other users in the generation and use of climate adaptation science (following Few et al. 2007). This is based on the belief that when implemented effectively, participatory research approaches enhance the extent to which scientific processes are perceived by stakeholders as credible and legitimate, increasing the potential for the information produced to be trusted and accepted by diverse stakeholder groups (Cash et al. 2006; Reed 2008). An important perspective on participatory research points to the underlying philosophy of the research approach being what differentiates it from more conventional academic research. "[T]he key element of participatory research lies not in methods but in the attitudes of researchers, which in turn determine how, by and for whom research is conceptualized and conducted" (Cornwall and Jewkes 1995 p. 1667). In other words, stakeholders are not just participants in the process, they are the reason for the research process - developing solutions to their problems is the core function of participatory research. Additionally, participatory research approaches can help adaptation science integrate the multiple perspectives and knowledge critical to decision-relevant research so as to tailor adaptation strategies to the needs of research users and the socialecological contexts for its application (Adger et al. 2005; Cornell et al. 2013).

Despite increased advocacy for the implementation of participatory research approaches in relation to climate adaptation, our understanding has remained largely uncritical (Lemos et al. 2018). While significant and important advances have been made in relation to (i) developing a typology of participatory research approaches (e.g. Meadow et al. 2015) and (ii) identifying the underpinning characteristics that are required for the implementation of successful participatory research approaches (e.g. van Kerkhoff and Lebel 2015; Wyborn 2015; Beier et al. 2016), comparatively fewer studies in the climate adaptation literature 
have sought to critically evaluate or understand the extent to which participatory research approaches pose additional challenges and risk to participants involved in the process (but see Harris and Lyon 2014; Gaziulusoy et al. 2016). Understanding the suite of potential challenges associated with participatory research approaches is critical for identifying the subsequent risks, and developing strategies to manage these so as to enhance the likelihood that participatory climate adaptation research will meet its desired goal of helping society successfully navigate modern day climate challenges.

To address this gap, we draw on the published literature (via a narrative review informed by our own experiences working within climate adaptation participatory research projects) to identify and explicate potential challenges created through participatory research to climate adaptation science, key actors groups including scientists and policy-makers, and research funders. While we acknowledge that there are other societal actors who can (and should) play a critical role in participatory adaptation research processes, for whom there are also risks that should be considered, we choose to focus on these three types of actors in this instance to allow for the detailed exploration of key issues and to identify specific strategies for managing the identified risks. We hope that by starting to explore these issues we will encourage researchers and practitioners to undertake future research to understand how the risks associated with participatory research are increased for other actors, and identify strategies for how they can be managed.

In writing this manuscript we acknowledge that the interface between science and policy is highly contextual and varies widely across geographies, cultures and temporal scales. Our goal in writing this manuscript is not to provide an in-depth analysis at any of these specific interfaces, but rather, to identify the potential challenges associated with participatory research more generally, and propose strategies for managing them, to help maximise the benefits resulting from participatory climate adaptation research processes (following Lacey et al. 2018). In this article we characterise these challenges through the language of 'risk', as this infers that the challenges can be both known and managed, though the level of concern about risk will differ depending on how it is perceived (e.g. Slovic 1987). We also 
acknowledge that this manuscript is informed by our personal experiences working primarily within Western cultures and developed nations, and thus the recommendations are most applicable within comparable research contexts, with potentially limited application to other contexts. To this end, we encourage other researchers and practitioners who are engaging in participatory adaptation research in different cultural settings and sectors to build on our efforts here and similarly share their experiences. Finally, while we focus our examples on climate adaptation, many of the challenges identified, and solutions posed, are likely to be applicable across all fields of participatory sustainability science.

We first (Section 2) provide a brief overview of participatory research to understand its origins and how it has evolved into practice in relation to climate adaptation research. This includes a review of the posited benefits associated with the implementation of participatory research approaches. Then (Section 3), we explore the potential challenges and risks associated with participatory research approaches to adaptation (i) science, (ii) scientists and scientific institutions, (iii) decision-makers and decision-making institutions, and (iv) research funders. Finally, in Section 4, we identify a range of strategies for managing the risks to increase the likelihood of success for participatory climate adaptation research.

\section{Overview of participatory research}

\subsection{A short history of participatory research}

Participatory research is an approach that involves the active engagement of diverse stakeholders in the research process. Participatory approaches to research arose as early as the 1940s (Lewin 1946; Tax 1958) as a response to positivistic notions in the sciences that excluded many voices and sources of knowledge, particularly local, indigenous, gender, and ethnic minority knowledges (Brown and Tandon 1983; Park et al. 1993; Greenwood and Levin 2007; Wallerstein and Duran 2008). A set of research approaches - including action research, participatory action research, practitioner research, emancipatory research, and community-based participatory research - has developed since that time to address a 
variety of social, environmental and health problems facing on-the-ground stakeholders and decision-makers. The whole suite of participatory research approaches intends to make research both more democratic, through stakeholder involvement, and impactful, by tying it to actions that benefit those stakeholders (Reason and Bradbury 2008a; Wallerstein and Duran 2008).

With the overarching goal of enabling informed change by engaging different stakeholder groups within research activities (reviewed by Khanlou and Peter 2005), participatory research focuses on engaging decision-makers and other stakeholders in research, not as subjects, but as co-producers of knowledge (Greenwood and Levin 2007; Reason and Bradbury 2008b). While this aspiration for egalitarian partnerships is not always met in practice (Wiber et al., 2004), the principles underlying this branch of research centre on notions of equality, co-production, and social and environmental justice, enacted through a mutually respectful and beneficial relationship between researchers and research stakeholders.

Stakeholder involvement in research can take a number of forms starting with low levels of engagement such as providing data for a research project or providing evaluative feedback on research products (i.e., consultation), to higher order engagement where research stakeholders inform the development of research questions and contribute to the setting of research agendas (Figure 1) (Reed 2017). Consultative approaches, however, can be limited in their use given that stakeholders often remain a source of information for use by researchers, rather than partners in the research process. As a result, these approaches do not guarantee the full development of the relationship between the producers and users of research, potentially undermining the extent to which the benefits of participation are conferred (see Section 2.2). 


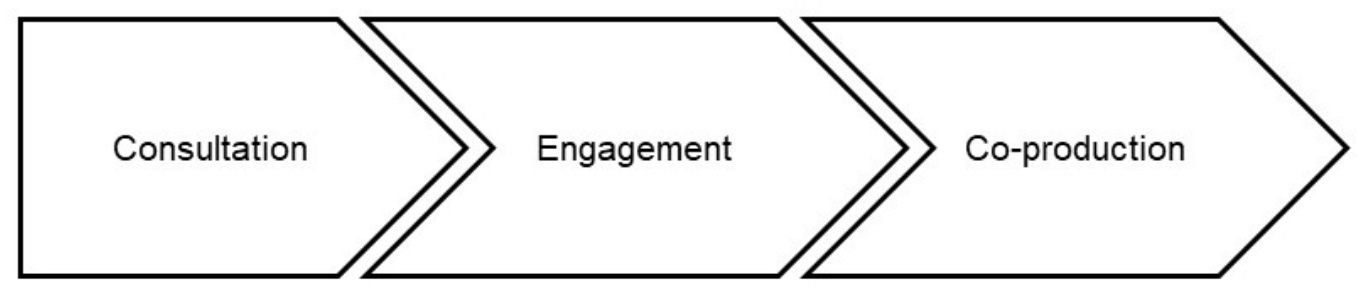

Stakeholders as inputs

Stakeholders as partners

Figure 1: Conceptual representation showing how the involvement of stakeholders in participatory research can take a variety of forms from consultation to co-production.

It was these shortcomings that encouraged the development of the broad field of participatory research. The practice developed largely in the social and health sciences, but in more recent decades, the practice has been explored in the biophysical and environmental sciences as a way to address increasingly complex environmental problems like climate change adaptation. Co-production of knowledge (Jasanoff 2004) has become a common term within the climate change adaptation field used to capture the idea that solutions to complex problems require interaction and co-production of solutions between science (researchers) and society (stakeholders). In this model, researchers and research stakeholders interact directly via trusting relationships and with shared goals. A recent review of the literature by Bremer and Meisch (2017) showed significant increases in the number of publications relating to climate change and co-production over the past two decades. Similarly, Meadow et al. (2015) also note the proliferation of supposedly coproduced climate knowledge.

Participatory research can also be facilitated through intermediaries such as boundary organisations (Guston 2001) and knowledge brokers (Meyer 2010). While conceptualised differently across sectors and settings, the key feature of these intermediaries is to facilitate the exchange of knowledge between various stakeholders, including researchers, practitioners and decision-makers. This is achieved by developing networks among these groups of stakeholders and facilitating their active involvement within research activities (Reinecke 2015). Indeed, the use of intermediaries in relation to climate challenges has 
increased, for example, in the United States with Jacobs (2014) identifying the NOAA Regional Integrated Sciences and Assessments program, the Climate Adaptation Science Centres funded by the Department of the Interior, and the 'climate hubs' of the US Department of Agriculture as recent examples of successful boundary organisations (Bednarek et al. 2018). Similarly, in Australia, recent empirical evidence has shown that a single knowledge broker was able to facilitate a cohesive network of climate scientists and decision-makers to promote increased participation and knowledge sharing (Cvitanovic et al. 2017).

Finally, participatory research can also be facilitated via novel institutional structures that 'embed' scientists within decision-making agencies, or vice versa (sensu Cvitanovic et al. 2015a). For example, Cook et al. (2013) posit that if decision-making agencies were to permanently embed research scientists within their organisations it would improve the likelihood that priority knowledge gaps will be filled, with the information quickly spreading among decision-makers and informing decisions. In this way the idea of embedding builds on that of knowledge co-production, in that it allows for decision-makers and scientists to collaborate more intensively through all aspects of both the scientific and decision-making processes. Furthermore, the embedding approach facilitates the implementation of long term participatory research activities and strategic collaboration across timescales better aligned with the challenges presented by climate change (i.e. beyond the scope of a single project) (Doubleday and Wilsdon 2012; Reed et al. 2014).

In summary, the core goals of participatory research are to co-produce knowledge and solutions with, and for, decision-makers and other stakeholders. In practice, a continuum of participation may occur, from stakeholders as inputs to research projects through models of co-production where the stakeholders actively partner with researchers in the research process, based on the specific questions and context of any given research project. Means such as the use of intermediaries and boundary organisations and institutional embedding can facilitate the novel and more intensive approaches to participatory research. 
Alongside the development and implementation of the different approaches to participatory research, an extensive body of literature has also emerged outlining a range of benefits associated with their application. One key benefit is that participatory research approaches overcome known barriers to knowledge exchange among scientists and decision-makers to support evidenced-informed decision-making (review by Cvitanovic et al. 2015a). In this section we provide a brief overview of these benefits.

First, participatory research approaches can be an effective way to make science more accessible to decision-makers and facilitate its incorporation in the decision-making processes. For example, studies across different environmental sectors have shown that on average it takes more than three years for scientific articles to be published following data collection (Fazey et al. 2005), and thus information may be out of date and less useful to decision-makers by the time it is made available (Linklater, 2003; Cvitanovic et al. 2016b). Furthermore, even when scientific knowledge does become available the majority is retained behind journal subscription paywalls which many decision-making agencies cannot afford (e.g. Cvitanovic et al, 2014b), thus further limiting its accessibility to, and utility in, decision-making processes. To illustrate, a recent analysis by Bornmann et al. (2016) found that only $1.2 \%$ of published climate change research has been cited in policy documents. Participatory research approaches are believed to help overcome these barriers, as the direct involvement of decision-makers and other end-users in the scientific process ensures that the research undertaken is solution-driven and useful for the decision-making context (Bednarek et al 2018). Additionally, these approaches can help decision-makers develop a real-time and in-depth understanding of the research content, which they can then disseminate quickly and effectively throughout their social networks and organisations as the information emerges (Reed et al. 2014).

Building on this, participatory research approaches are believed to increase the extent to which the outcomes of scientific research are perceived by decision-makers as salient, credible and legitimate (Cash et al. 2003). In this regard, salience describes the extent to 
which the research outcomes are relevant to decision-makers and specific decision-making contexts, taking into consideration their specific information needs and institutional operating environments (Cash and Moser 2000). Credibility refers to the extent to which scientific outputs and outcomes are perceived by decision-makers as accurate, valid, robust and of high quality (Cash and Buizer, 2005; Salter et al. 2010) while legitimacy describes the extent to which the knowledge producers (i.e. adaptation researchers) are considered to be bias free and thus trustworthy by decision-makers (Deelstra et al., 2003). In combination, it is believed that these three traits increase the likelihood that scientific outcomes will be incorporated into decision-making processes (Cash et al. 2003), particularly in relation to complex and contested issues such as those associated with climate change and the array of available adaptation options to decision-makers. For example, as detailed in Lacey et al. (2015), there are numerous uncertainties associated with how adaptation options are selected for implementation, such as the choice of appropriate methods for downscaling global or regional models to inform adaptation at the local scale (Hewitson et al., 2014). This, in combination with the ways in which different researchers define and respond to adaptation (e.g. considering technological innovation versus institutional change), creates the risk that researchers may become advocates for their own work without full transparency that their recommendations represent only a subset of the available knowledge and adaptation options that are available. In such cases there is the potential that adaptation science will not be utilised, or will lead to suboptimal outcomes, thus highlighting the importance of salience, credibility and legitimacy in relation to adaptation science.

Next, participatory research approaches can facilitate the inclusion of multiple knowledge systems into decision-making processes (Mauser et al. 2013; Tengö et al. 2017). This is important given that scientific knowledge is only one form of knowledge system that can contribute to informing adaptation decision-making processes, and in recognition that adaptation science is most useful to, and trusted by, decision-makers when considered in conjunction with other forms of knowledge (Cornell et al. 2013; Cvitanovic et al. 2014a). For example, the inclusion of local and cultural knowledge is critical for identifying the most appropriate and culturally sensitive fine-scale adaptation options, and subsequently for 
understanding how to engage with local communities to promote their uptake (Reid et al. 2009; Gearheard et al. 2010; Naess 2012; Boillat and Berkes 2013). Similarly, the inclusion of experiential knowledge is believed to enhance the likely success of decision-making processes as it allows those engaged in participatory research approaches to learn from previous successes and failures (e.g. in relation to the communication and subsequent acceptance of adaptation options by end-users), thus increasing the potential for success of decision-making processes (Fazey et al. 2006). Finally, the integration of expert knowledge through formal expert elicitation techniques can be used effectively to support decisionmaking under uncertainty and in scenario modelling of uncertain future events, particularly when quantitative scientific evidence is lacking (Hemming et al. 2017; Martin et al. 2012). Thus, bridging diverse knowledge systems through participatory research has also been shown to generate innovative, more inclusive and equitable solutions to sustainability problems, such as those arising from climate change (Mauser et al. 2013).

Finally, participatory research approaches are recognised for their ability to foster learning among participants (reviewed by Gupta 2016), which we define as 'the process of cognitive change leading to behavioural change, which can manifest at either individual or collective scales' (following Newig et al. 2010). Essential to this shared learning via participatory research is the direct interface between researchers and research stakeholders. By creating a space where the research 'producer' and 'user' build meaningful relationships that break down the intergroup divide - turning 'us and them' into 'we' - researchers and research stakeholders are more likely to experience trust (Lacey et al. 2018), a sense of shared identity and purpose (Fielding and Hornsey 2016; Colvin et al. 2015), and social influence that increases "receptiveness to the views of those whom we regard as 'one of us'" (Mols et al. 2015, pp.89-90). This relationship building enables learning in the immediate term (e.g. via a distinct project) and in the longer-term (e.g. via ongoing collaboration and interaction) ultimately enhancing outcomes for climate adaptation researchers and research stakeholders alike. Learning is considered particularly important for navigating the uncertain, complex and synergistic challenges presented to society by climate change (Sardar 2010; Parrott and Meyer 2012; Picketts 2018), as it underpins the extent to which 
decision-makers and their associated governing institutions can respond rapidly, adaptively and flexibly to change (Fazey et al. 2007).

\section{Challenges and subsequent risks of participatory climate adaptation research}

Arguably, all applied research - in which our suppositions and experiments are subject to real-world tests - is a risky endeavour. We remove the protective boundaries of a tightly controlled laboratory and grapple with the messy world in which science and society interact and intermix constantly. However, participatory research poses some additional challenges because it actively includes multiple perspectives, voices and values in ways that make data collection, analysis and interpretation much more complicated than the traditional laboratory situation. In some cases, these additional challenges may also confer additional risks to the actors taking part in the participatory research process. Thus, as the use of participatory research approaches grows in climate adaptation work, we must consider the challenges and risks in ways that have not yet been done within the climate adaptation community, so as to identify options for managing them, in turn ensuring that adaptation science can fulfil its objective of helping society achieve the transformative changes that are required. To this end, in this section we draw on the existing literature and our own experiences operating in participatory research projects to undertake a critical examination of the challenges associated with participatory research approaches and the risks that they may confer. While our list is not exhaustive, it serves to highlight some of the key challenges associated with participatory research processes about which participants should be mindful.

\subsection{Challenges to the scientific process}

\subsubsection{Compromised scientific integrity}

First, participatory research approaches may generate some additional challenges and risks to the scientific process with regards to both the 'quality' and 'utility' of the scientific outcomes, as are commonly understood in the natural and physical sciences where much climate research is based. Every participant engaging in participatory research approaches 
has a set of beliefs about what constitutes knowledge, how it is produced and how it should be applied (i.e. their epistemological perspective) (Blythe et al., 2017). Participatory research depends on these multiple perspectives - including the unique perspective of the researchers - to increase the external validity of research (i.e. its applicability to solving realworld problems) (Green et al. 2009). However, balancing and incorporating multiple, and possibly contradictory, perspectives in ways that maintain the credibility of the science poses both philosophical and practical challenges.

The inclusion of multiple participants within the research process and the associated combination of knowledge systems, may appear to compromise the actual and/or perceived integrity of the scientific outputs (Mauser et al. 2013; King and O'Meara 2018). For example, while it is generally argued that addressing contemporary climate adaptation challenges requires the integration of knowledge systems (e.g. local knowledge, experiential knowledge, cultural knowledge, etc.), non-scientific knowledge can be perceived by some as more susceptible to bias or lacking in credibility. Thus, the inclusion of a diversity of knowledge systems, without careful and ethical research practices, presents a real or "perceived" risk that biased or un-interrogated beliefs could undermine the perceived rigour of research outputs. This, in turn, could reduce the extent to which decision-makers trust the research outcomes and/or outputs, making it less likely that they incorporate them into their decision-making processes.

\subsection{2 'Containment' of actors}

Power imbalances can also play a role in the ways that multiple and diverse perspectives are incorporated credibly in a participatory research process (Few et al. 2007). For example, where epistemological perspectives among participants are mutually exclusive, some forms of knowledge (e.g. scientific, experiential, local) and research methodologies (e.g. quantitative vs qualitative vs mixed-methods approaches) may be disregarded or distrusted by some research participants (Blythe et al. 2017). This has the potential to disrupt the collaborative research effort, and lead to the dominance of one knowledge system over the others (Balvanera et al. 2017). In these situations, the more 'powerful' individuals or groups 
can consciously or subconsciously steer participation towards support for a specific epistemology, method, or even a predetermined outcome, by forging tactical alliances and blocking dissent; termed 'containment' of participation (Few 2001; 2003). This means that research outcomes are less likely to have been informed by the full suite of available knowledge, reducing its usefulness to assist in informing adaptation decision-making processes, or potentially leading to maladaptive decision-making processes.

Further, in many cases of participatory research it is those who are managing the participatory process that are in the privileged position of deciding who is considered a legitimate participant and who is not, in turn potentially elevating some perspectives and excluding others (Colvin et al. 2016). Other types of power, too, can influence the success of participatory research. For example, Reed (2016) encourages researchers to consider their relative power in participatory processes, including their situational power (formal, hierarchical, power), social power (privilege due to gender, race, sexuality etc.), personal power (personal traits such as trustworthiness, charisma) and transpersonal power (access to powerful others). Reflecting on power dynamics in a participatory research setting can identify where the reality of - or perceptions about - power creates expectations that can be conducive or inhibiting to effective participatory research. Where power is used to create an unfair advantage for certain groups or ideas, whether intentionally or unintentionally, it puts the legitimacy of the process and the credibility of the science at risk, limiting its utility for decision-making processes and broader societal responses to adaptation.

\subsubsection{Tokenistic engagement}

There is also a risk that participants could simply be engaged within participatory research approaches on a tokenistic level (Arnstein 1969) - in which case the research may no longer be considered as participatory. For example, as calls for science to fulfil its societal obligations have increased (e.g. Lubchenco 1998), so too has the requirement by research funders for research proposals to be 'transdisciplinary', and actively engage decisionmakers. It is now commonplace that research proposals are submitted describing a 'high level participation' between the research team and decision-makers (e.g. Watermeyer and 
Hedgecoe 2016). However, the extent to which high levels of participation occur in practice may be limited, compromising the overall success of the process and reducing the validity of the outputs and outcomes.

\subsection{Challenges for adaptation scientists and scientific institutions}

\subsubsection{Compromised individual integrity}

Participatory research approaches can also present significant challenges to adaptation scientists. For example, as outlined in section 3.1, the inclusion of multiple epistemological perspectives that results from participatory research approaches has the potential to compromise both the actual and/or perceived integrity of the scientific outputs (e.g. Supran and Oreskes 2017; King and O'Meara 2018). In this respect, social science practitioners of participatory research and those beginning to use the approach in climate adaptation are in agreement - the perception from other researchers that applied, participatory research is somehow less rigorous or "scientific" is a recurring theme and challenge (Greenwood and Levin 2007; Polanyi and Cockburn 2003; Schensul et al. 2014). This has the potential to adversely impact the individual reputation of researchers (e.g. reputational risk) engaged in participatory research processes among their peers and decision-makers in the field. This may, in turn, limit their opportunity to collaborate with peers, or the extent to which their research outputs are trusted and used in decision-making processes outside of the group with whom the researchers directly collaborated with on the participatory research project.

\subsubsection{Impacts on career progression}

Current incentive systems in academia result in a researcher's reputation being largely dependent on their academic achievements (e.g. quality of their peer-reviewed publications and funding success). It has been shown that research involving multiple epistemological perspectives has consistently lower funding success than more traditional modes of research (Bromham et al. 2016), and is typically more challenging to publish in top tier scientific journals as many journals are discipline-specific and those that are not find it difficult to find reviewers who span multiple epistemological perspectives (Campbell 2005; 
475 Rafols et al. 2012). Given that funding success and publication in top tier journals remain a

476 key measure of academic performance (e.g. Cvitanovic et al. 2015b), utilising participatory

477 research approaches can confer risks to adaptation scientists via impacts to their job

478 security, career progression and success in science.

The implementation of participatory research approaches also has significant complexity and transaction costs (Beier et al. 2016; Balvanera et al. 2017) that can present a number of challenges to career progression among adaptation scientists. Firstly, negotiating the various perspectives of different stakeholders involved in the process (and accounting for their institutional requirements such as approvals and internal review processes) can be time consuming (Polk 2015). Time spent traveling and attending meetings in addition to the standard travel requirements of research (e.g. field work) also means time away from other competing academic demands (Hoeft et al. 2014). These transaction costs present a risk to scientists as they could ultimately impede progress of scientific outputs by extending the time before publication of results, which as described above, can have subsequent impacts on career success and progression. In contexts where there is poor institutional acceptance of, and support for, extended timeframes associated with participatory research, it may lead to the perception that scientists are 'under-delivering', once again adversely affecting the ability of adaptation researchers to seek permanency or promotion.

\subsubsection{Impacts on personal well-being}

Closely related to the above, increased process complexity and the associated transaction costs can also impact on the work-life balance of adaptation scientists (Campos-Arceiz et al. 2013). For example, increased travel requirements and attendance at prolonged meetings and workshops can limit the time that adaptation scientists spend with family and friends. This, in turn, may lead to strained, or lost, relationships. Long and non-typical working hours, such as those associated with excessive travel, are also known to be risk factors for depression and anxiety (Kleppa et al. 2008; Virtanen et al. 2011). 
Furthermore, the range of skills and experiences required to navigate and negotiate complex participatory processes (ability to read social cues, navigate complex political settings, etc.) are not taught as part of traditional academic training programs (Bernstein et al. 2017) or considered legitimate forms of academic scholarship (Jacobson et al. 2004). As such, some adaptation researchers might find engaging in such processes particularly challenging and stressful, or even unnecessary, thus limiting their levels of professional confidence and satisfaction. This compounds with existing stressors on personal wellbeing for researchers, which in a more standard model of science, are already not insignificant (Reevy and Deason 2014).

\subsubsection{Decreased 'trustworthiness'}

Engaging in participatory research approaches may also limit the extent to which adaptation researchers are perceived outside of their group as 'honest brokers' (sensu Pielke 2007). As described by Pielke (2007), the notion of honest broker describes a sub-set of scientists who do not advocate for a single cause or pre-determined outcome, but rather consider the full suite of available information to provide factual, empirically-based advice that does not reflect their individual research or epistemological perspective.

In instances where adaptation researchers work closely with specific decision-makers for long periods of time, they might be perceived by other stakeholders and end-users as losing their objectivity, lessening the extent to which they are considered an honest broker, and thus, their potential impact on decision-making processes more broadly. For example, adaptation researchers (and by association their colleagues and institutions) who have collaborated closely with industry may not be viewed as credible by environmental NGO stakeholders or other scientists and institutions who choose not to engage with industry, and vice versa. In such situations, the boundary between researcher and research stakeholder blur to the point where perceptions about the research stakeholder's motives, conduct and credibility are transferred to the researcher, regardless of the nature of scientific integrity and rigour underpinning the researcher's work. 
Participatory research approaches can also present several challenges and risks to decisionmakers that engage in them. Firstly, they can increase the likelihood of situations whereby an individual scientist (or group of scientists) 'capture' decision-makers who then continue to support and fund a specific stream of research that aligns to the disciplinary or epistemological lens of that specific scientist group (Lacey et al. 2018). This can have adverse impacts for both individual decision-makers and the broader decision-making agency. For example, for highly complex and uncertain challenges such as those presented by climate change, a focus on singular dimensions of the issue may lead to missed opportunities or even maladaptation (Lacey et al. 2015). This may also lead to increased scrutiny of the individual decision-makers engaged within the participatory research process, and of the broader decision-making agency. This has the potential to adversely impact individual careers and cause individual distress, while potentially also impacting broader societal support for, and trust in, the decision-making institution.

\subsubsection{Loss of perceived legitimacy by public}

Building on the above, when dealing with controversial and complex issues such as those associated with climate adaptation (Boykoff 2007), the likelihood of divergent perspectives among participants is heightened. This may lead to dissent among participants and conflict may arise (Colvin et al. 2015). In such cases there is the risk that adaptation researchers, who are not bound by organisational limitations, may speak out publicly in opposition to the decision-makers' public position, leading to a loss of public support for the agency (Picketts 2018). Where this occurs there are also risks to individual decision-makers associated with distress and mental health, as well as to the broader decision-making agency by affecting the extent to which they are perceived as legitimate by their stakeholders and the broader public (Tyler 2006). However, we acknowledge the important role of researchers in challenging decisions that may go against best available evidence or fail to represent the 
public good. Nevertheless, when these dynamics arise in a participatory research setting the potential risk to decision-makers is heightened. From the decision-makers' perspective, inviting researchers into the decision-making process necessarily makes the decision-maker vulnerable to researchers with privileged knowledge of the decision context and process using that knowledge to act as powerful adversaries in the public sphere.

\subsection{Challenges to adaptation research funders}

\subsubsection{Increased (potentially unjustifiable) costs}

Finally, participatory research approaches can also present additional challenges to funders of climate adaptation research. For example, the increased number of participants, who are also likely to be geographically dispersed, associated with participatory research approaches can lead to increased implementation costs (which is the cost of coordinating implementation and the potential opportunity cost of implementation failure) (Birner and Wittmer 2004). At the same time it will also increase decision-making costs (cost of acquiring information, cost of coordinating decision making and decision-failure cost) and production costs (technical measures needed to manage the research or implementation of the outputs) (Birner and Wittmer 2004; Sutherland et al. 2017). Thus, where the benefits achieved through participatory research approaches do not outweigh their additional costs the funders are likely to be increasingly scrutinised with potential impacts to their public credibility, particularly in instances where funding is provided via public monies (e.g. government grant schemes).

Compounding this risk is that many collaborative processes necessitate expenses that may be more open to public critique, compared with traditional laboratory-related costs. This includes costs from catering for workshops and meetings, and the travel and accommodation associated with relationship building as opposed to a physically tangible deliverable. The potential intangibility of the activities, as well as the costs, associated with participatory research may create difficulties for research funders in justifying their funding choices to relevant actors. 


\section{Strategies to manage risk in participatory research}

593 Despite widespread advocacy for the implementation of participatory research approaches

594 in relation to climate adaptation, we have outlined how they can also present significant 595 challenges and risks to adaptation science, scientists, decision-makers, and funders.

596 Identifying and implementing strategies to reduce and manage these risks is critical to 597 ensure that the perceived benefits of participation are realised. In this section, we review 598 the literature from other sectors where participatory research approaches are commonly 599 implemented (e.g. the medical sector and private sector), to provide insights and strategies 600 for how to manage risk and maximise the potential for success of participatory climate 601 adaptation research (Figure 2; Table 1). In doing so, however, we reiterate our earlier point that these strategies have been informed by the various experiences of the author group who primarily work within Western and developed cultures and contexts. Thus, their applicability is best suited in comparable contexts, and future work is needed to understand how they could also be applied across broader cultures and contexts, or what other mechanisms are available for other contexts.

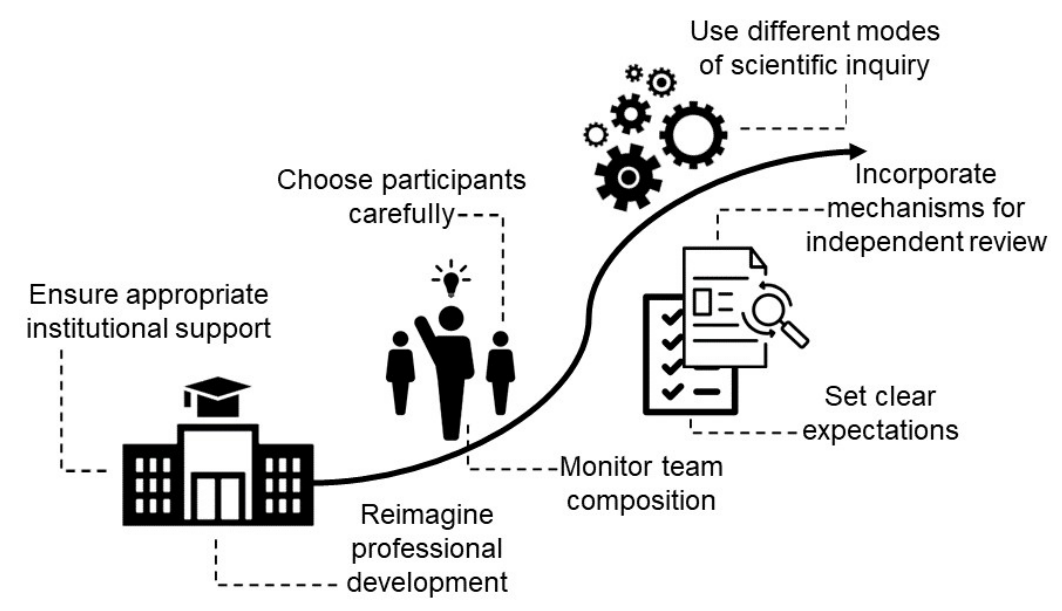

Figure 2: Visual representation of the seven strategies that can be used to manage the challenges and risks of participatory adaptation research. with participatory research approaches is largely dependent on the composition of 
the group. However, it has been shown that achieving an appropriate balance in group composition is highly variable according to individual characteristics of the participants as well as the social and political context within which the science is to be produced (e.g. Eckley 2002; Farrell and Jäger 2005). While it is difficult and sometimes undesirable to manipulate and/or change social or political contexts, steps can be taken to ensure that participants display the required individual attributes to minimise risk and maximise the likelihood of success (Timmings et al. 2016). For example, it is critical that all participants, despite their individual epistemological perspectives, are open to the perspective and worldviews of the other participants (Eckley et al. 2001; Evans and Cvitanovic 2018). It is also critical that the group is sufficiently context specific to represent the perspectives that are relevant to the research or decision context, and that representation across groups is balanced to reduce the likelihood of a power imbalance. In sum, it is important to ensure that access to participatory research is open to all stakeholders with appropriate expertise, reflecting principles of equity of access and inclusion. However, given the necessity of inter-personal trust, it is also important to take seriously the need to address and appropriately deal with participants who may undermine or exclude other participants from a different background during the process (whether it be personal, disciplinary, or otherwise).

Adopting approaches which explicate identification processes is, therefore, important for ensuring all relevant participants are identified, not just those who may be familiar or easily accessible to the adaptation scientists or decision-makers (Colvin et al. 2016). To achieve this, in developing teams the initiators (be they adaptation researchers or decision-makers) could use stakeholder analysis techniques (see review by Reed 2008) to identify all relevant (i.e. context specific) stakeholders, the existing relationships that exist among them and the potential level of influence and/or power that they might have in the group.

Appropriate researcher training and capacity development is also a key consideration (Hegger and Dieperink 2014; Meadow et al. in review; Wiek et al. 2011). Indeed, inadequate preparation and training of researchers to conduct 
participatory research is a key risk to the process (Grant et al. 2008). Given that effective participatory research depends on transparent and trusting relationships among all team members, it is critical that researchers have adequate communication, facilitation and group-process skills in addition to their research and academic skills (Grant et al 2008; Addison et al 2013). Further, Cheruvelil et al. (2014) highlight the ways in which teamwork training (via both formal and informal avenues) can promote a collaborative environment and increase the likelihood of success in solving complex environmental challenges. Thus, by incorporating specific skills that support team building initiatives and activities throughout the project (e.g.

b) Monitor team composition and adjust: Despite best efforts to ameliorate risks via the careful selection of participants, participatory research approaches can be highly informal team meetings, formal team and trust-building initiatives, etc.), collaboration and productivity can be enhanced over the duration of the project. dynamic over time, for example; given changing social and political settings, changes in the personal circumstances of participants, or conflicts that may arise (Sarkki et al. 2014). As such, it is critical that the team composition, and the extent to which it is functioning effectively, is monitored and adjusted as needed over time (Djenontin and Meadow 2018). This could be achieved via the implementation of longitudinal social network analysis (e.g. Cvitanovic et al. 2017), which is a cost effective approach to monitor the role and influence of the various participants according to their 'position' within the overall network, and how these change (Crona and Bodin 2006; Bodin and Crona 2009). Schulz et al. (2003) also recommend annual surveys to monitor group dynamics and adjust processes to ensure projects remain productive. Such surveys may include evaluation of whether team members feel they are part of one coherent whole (i.e. a 'we') or see themselves as belonging to a number of fractured groups (i.e. 'us and them') (e.g. Haslam et al. 2003). Doing so will allow for the early identification of potential issues that may emerge, such as 'powerful' individuals or intergroup conflict, so that collective action can be taken to remedy the situation. 
Furthermore, ongoing monitoring of the group composition should include regular (e.g. annual) stakeholder analyses to assess whether the participants represent all the relevant stakeholders. This will ensure that even as social and political situations change, all relevant stakeholders groups are correctly represented. While individual team members may change over time in response to the broader needs of the group, because participatory research often depends on long-term relationships, "the goal ... is to generate networks that are sufficiently strong that members can come and go without threatening the cohesiveness of the overall partnership" (Austin 2004, P. 427).

c) Set clear expectations and agreed conflict resolution mechanisms: Once the team has been identified, it is important to collectively set and agree upon the expectations associated with the participatory research effort. These expectations should look beyond simply agreeing on joint outputs of the research by also focusing on expectations relating to individual behaviours and conflict resolution mechanisms for the entire research process. Indeed, developing conflict resolution mechanisms for highly collaborative groups such as those embodied by participatory research approaches is particularly challenging, given a potential lack of access to external and fully independent conflict-resolution mechanisms (Alston et al. 1999). Thus, agreeing on and documenting a shared set of conflict resolution options at the outset is critical (Margerum 2002). For example, establishing multi-stakeholder decision-making groups under specific and explicit rules around collaboration and the necessity for productive outcomes was found to facilitate effective participatory decision-making in high-conflict settings (Colvin et al. 2015). Furthermore, given that the majority of climate adaptation research requires research ethics approval, conflict resolution measures could be included within ethics applications so that there are options to seek external support should the conflict not be able to be resolved among the members of the participatory research process (Khanlou and Peter, 2005).

\section{d) Utilise different modes of scientific inquiry to address different knowledges and}

biases: As highlighted through the experiences of social science practitioners of 
participatory research, reflexive and interpretive modes of inquiry that directly consider the tensions between different viewpoints as part of the research process should be used (Wallerstein and Duran 2008; Fazey et al. 2018). That is, treating participatory research as a research practice, not a public participation effort - in order to balance and integrate multiple perspectives. For example, using multiple lines of inquiry such as one-on-one interviews, focus groups, surveys and participant observation helps researchers better understand how and why the multiple perspectives exist and provides opportunities to triangulate information and accounts received from participants. This process of triangulation and reflection can also be combined with an iterative and reflexive analysis process involving researchers and stakeholders to ensure that power imbalances are managed and that the different knowledge systems are equally accounted for (e.g. van Kerkhoff and Pilbeam 2017).

Reflective and interpretive modes of scientific enquiry also point to the need for researchers to consciously encourage all participants to examine their values and views as part of understanding the larger problem and potential solutions. Specifically, and as described by Huntjens et al. (2014), the researcher should play a different role from the stakeholders in order to ensure that the added value of the researcher in the process is maintained. One aspect of that role, according to Greenwood and Levin (2007, P. 54) is that action researchers are "obligated to question [local stakeholders], press their logics and interpretations ..." and "reflect back to the local group things about them, including criticism of their own perspectives or habits, in a way that is experienced as supportive rather than negatively critical or domineering". Tools like facilitation can also be used to help the group as a whole avoid overemphasis of a single perspective or knowledge base (Mackewn 2008).

In addition to reflexive and interpretive modes of inquiry, in collaborations designed to support decision-makers through a participatory process, other approaches such as structured decision-making can be used. Structured decision-making involves structured processes for scientists to follow from defining the decision context 
through to exploring and implementing adaptation options, monitoring and evaluating effectiveness of implemented adaptation activities (Addison et al. 2013). Most importantly these approaches involve facilitation techniques and tools to elicit carefully both factual information (e.g. about the state of the environment) and values (e.g. individual priorities or preferences), whilst accounting for biases and uncertainty within these knowledge systems (e.g., Addison et al. 2013; Hemming et

\section{e) Incorporate mechanisms for independent review at all stages of research: In} addition to the strategies outlined above that can be implemented by the research team itself, risk in participatory research approaches can be further managed via independent reviews. As reviewed by Khanlou and Peter (2005), independent reviews ensure that individuals who are unaffiliated with the research project have the opportunity to evaluate the project to ensure that it meets its desired scientific outcomes in an ethical manner, further reducing any potential conflict of interest. In many cases, participatory research will be reviewed by human ethics review boards as part of standard academic practices. Indeed, it is for this reason that independent reviews are now common place within participatory medical research (Emanuel et al. 2000). To be most effective, independent reviews should be undertaken by multiple individuals throughout the scientific process, from the conceptual and design phase, through to the implementation of the research and the development of subsequent scientific outputs.

Independent reviews should not only be output focused, but also provide an evaluative mechanism on the overall functioning and dynamics of the team and various participants (e.g. Trimble and Lázaro 2014). It is also important to ensure that reviewers are familiar with the processes and practices of participatory research so as to avoid having the project evaluated inappropriately based on a misunderstanding of the credibility of participatory research (as discussed in section 3.1) (Polanyi and Cockburn 2003). Where independent reviews find that teams are not functioning effectively and risk has been created, steps should be taken to remedy the problem, by returning to the set of behavioural expectations agreed 
upon at the onset of the project, or if necessary, by drawing on the agreed conflict resolution mechanisms.

f) Reimagine professional development for adaptation researchers: While the above strategies are focused on practical steps that can be taken as part of the participatory research process, the challenges and risks can also be reduced and managed by reimagining professional development for adaptation researchers. For example, as highlighted in Section 3.2.3, the range of skills and experiences required to navigate and negotiate complex participatory processes are not taught as part of traditional academic training programs (Cvitanovic et al. 2015b). While academics in the social sciences are more likely to receive training in the participatory skills outlined above, training programs for natural and physical scientists to engage outside of academia are typically focused on improving one-way communication skills - opposed to those associated with active listening, mediation, brokering, facilitation and translation that underpin successful collaboration among diverse individuals/groups separated by epistemological perspectives (Addison et al. 2013, Bernstein et al. 2017; Bednarek et al. 2018). Thus, institutional innovation and structural changes with the academic system to support the development of these skills in adaptation scientists, and particularly with early career adaptation scientists, are needed (Lang et al. 2012).

This type of institutional innovation will not occur in a vacuum, but can build on recent advances in the past decades that promote transdisciplinary and participatory research. For example, there is an improved collaboration across disciplines and between science and society (Fischer et al. 2015). Funders are increasingly, albeit slowly, supporting participatory research and rewarding stakeholder engagement and practical impact. While these are still marginal trends, they are seeds of change that can stimulate broader transformation in the design of current research strategies and incentive systems that primarily reward disciplinary science that does not engage with society. 
g) Ensure appropriate institutional support: Finally, the challenges and risks associated with participatory adaptation research can be managed and reduced by ensuring that appropriate and sufficient institutional supports are in place to protect both researchers and decision-makers. For example, participants of participatory research approaches should have access to formal legal and financial advice throughout the process of contract development to ensure that mechanisms are in place to protect their reputation, credibility and intellectual property. For example, prior to the commencement of research activity, contracts should be developed that clearly stipulate the conditions of the collaboration/partnership (e.g. the right to publish research outputs, the right to withdraw from the partnership should any conditions be not met, agreed upon conflict resolution measures, etc.) in order to protect the reputation and intellectual property of all participating individuals as well as their institutions.

Institutions should also explicitly recognise the additional challenges involved in implementing participatory research approaches, and ensure mechanisms are in place to support their staff should challenges arise, for example, via the establishment of formal mentoring programs. Finally, in light of the challenges and risks outlined above, and the time/resources needed to navigate them successfully so that desired outcomes can be realised, institutions (and particularly research institutions) should encourage good research practice by clearly defining and resourcing stakeholder engagement expectations (Cvitanovic et al. 2015b). This should include incentivising this type of research through the establishment of adequate metrics of science impact that account for the full suite of responsibilities researchers have within participatory research approaches, so as to underpin promotions and career progression (Keeler et al. 2017)

Table 1: Summary of the seven strategies that can be used to manage the challenges and risks of participatory adaptation research.

Participatory research risk management strategy
Insights for implementing participatory research risk management strategy 


\begin{tabular}{|c|c|}
\hline Choose participants carefully & $\begin{array}{l}\text { - Include participants who are open and respectful to } \\
\text { the perspectives and worldviews of others. } \\
\text { Ensure that the group is context specific, with balanced } \\
\text { representation of all relevant stakeholder groups. }\end{array}$ \\
\hline Monitor team composition & $\begin{array}{l}\text { Monitor team composition over time to identify (and } \\
\text { rectify) sources of conflict and/or power imbalances. } \\
\text { - Undertake regular (e.g. annual) stakeholder mapping } \\
\text { to ensure that team members are 'representative' of } \\
\text { all relevant groups across life of project. }\end{array}$ \\
\hline Set clear expectations & $\begin{array}{l}\text { - At the onset, jointly set agreed expectations for both } \\
\text { the research process and individual behaviours of } \\
\text { participants within the process. } \\
\text { Also at the onset of the research activity, identify and } \\
\text { agree on a range of internal and external conflict } \\
\text { resolution mechanisms should conflict arise. }\end{array}$ \\
\hline $\begin{array}{l}\text { Use different modes of scientific } \\
\text { inquiry }\end{array}$ & $\begin{array}{l}\text { Where appropriate, use reflexive and interpretive } \\
\text { modes of enquiry that directly consider and account } \\
\text { for the tensions between different viewpoints. } \\
\text { Use independent facilitation where possible to avoid } \\
\text { the overemphasis of a single perspective or knowledge } \\
\text { base dominating group discussions. }\end{array}$ \\
\hline $\begin{array}{l}\text { Incorporate mechanisms for } \\
\text { independent review }\end{array}$ & $\begin{array}{l}\text { Plan (and ensure budget) for independent reviews } \\
\text { throughout the entire research process. } \\
\text { Ensure reviews focus on both the overall functioning } \\
\text { and dynamics of the team and various participants, as } \\
\text { well as research outputs. } \\
\text { - Where possible (e.g. within budgetary constraints), } \\
\text { include independent reviews from multiple } \\
\text { peoples/groups. } \\
\text { Ensure reviews have a strong understanding of the } \\
\text { processes and practices of participatory research. }\end{array}$ \\
\hline $\begin{array}{l}\text { Reimagine professional } \\
\text { development }\end{array}$ & $\begin{array}{l}\text { Research institutions should provide training and } \\
\text { capacity develop for adaptation researchers in the full } \\
\text { suite of skills required by participatory research, such } \\
\text { as those associated with active listening, mediation, } \\
\text { brokering, facilitation and translation. }\end{array}$ \\
\hline $\begin{array}{l}\text { Ensure appropriate institutional } \\
\text { support }\end{array}$ & $\begin{array}{l}\text { - Ensure adequate and expert legal and financial support } \\
\text { is available to participants during the development of } \\
\text { participatory research contracts. } \\
\text { - Research institutions should encourage good research } \\
\text { practice by clearly defining stakeholder engagement } \\
\text { expectations. } \\
\text { - Research institutions should recognise and reward the } \\
\text { full suite of responsibilities researchers have within } \\
\text { participatory research approaches. }\end{array}$ \\
\hline
\end{tabular}


836 Calls for the implementation of participatory research approaches have become commonplace in the pursuit of generating usable climate adaptation science that will be beneficially incorporated into decision-making processes. However, despite the many benefits of such research approaches, as we have highlighted through this review, their implementation also poses additional challenges for participants, in some cases with subsequent risks at personal, professional or institutional levels. These challenges, however, are not insurmountable, and in this paper we have drawn upon other sectors and disciplines where participatory research approaches are commonly implemented to start to identify strategies for managing these challenges, and reduce the risks they pose (outlined in Table 1). Underpinning all strategies is the central importance of relationships, trust, credibility and social learning, as researchers, practitioners, policy-makers and the broader community embark together on this new journey toward participatory knowledge generation and use. While the implementation of these strategies will need to be adapted to fit within specific contexts and processes, being mindful of the challenges associated with participation, and ways to manage them, will help enhance the benefits conferred through participatory research processes.

\section{Acknowledgements}

854 We thank Justine Lacey for insightful comments and discussions that greatly improved this manuscript. Financial support was provided by the Centre for Marine Socioecology at the University of Tasmania, Australia. PFEA is supported by the Natural Environment Research Council [NE/N005457/1]. We also thank the two anonymous reviewers who provided constructive comments that helped improve this manuscript.

\section{References}

Addison PFE, Rumpff L, Bau SS, Carey JM, Chee YE, Jarrad FC, McBride MF, Burgman MA (2013) Practical solutions for making models indispensable in conservation decisionmaking. Diversity and Distributions 19, 490-502.

Adger WN, Huq S, Brown K, Conway D, Hulme M (2003) Adaptation to climate change in the 865 developing world. Progress in Development Studies 3, 179-195. 
Adger WN, Arnell NW, Tompkins EL (2005) Successful adaptation to climate change across scales. Global Environmental Change 15, 77-86.

Alston LJ, Libecap G, Mueller B (1999) Titles, conflicts and land use: The development of property rights and land reform on the Brazilian frontier. University of Michigan Press, USA.

Arnstein S (1969) A Ladder of Citizen Participation. Journal of the American Institute of Planners 35 (4), 216-224.

Austin DE (2004) Partnerships, not projects! Improving the environment through collaborative research and action. Human Organizations 63, 419-430.

Balvanera P, Daw TM, Gardner TA, Martin-López B, Norström AV, Speranza Cl, Spierenburg M, Bennett EM, Farfan M, Hamann M, Kittinger JN, Luthe T, Maass M, Peterson GD, Perez-Verdin G (2017) Key features for more successful place-based sustainability research on social-ecological systems: a Programme on Ecosystem Change and Society (PECS) perspective. Ecology and Society 22(1), 14.

Bednarek A, Wyborn C, Cvitanovic C, Meyer R, Colvin R, Addison PFE, Close SL, Curran K, Farooque M, Goldman E, Hart D, Mannix H, McGreavy B, Parris A, Posner S, Robinson C, Ryan M, Leith P (2018) Boundary-spanning at the science-policy interface: The practitioners' perspective. Sustainability Science 13, 1175-1183.

Beier P, Hansen LJ, Helbrecht L, Behar D (2016) A how-to guide for coproduction of actionable science. Conservation Letters 10, 288-296.

Bernsten MJ, Reifscheider K, Bennett I, Wetmore JM (2017) Science Outside the Lab: Helping graduate students in science and engineering understand the complexities of science policy. Science and Engineering Ethics 23, 861-882.

Birner R, Wittmer H (2004) On the 'efficient boundaries of the state': the contribution of transaction-cost economics to the analysis of decentralization and devolution in naturel resource management. Environment and Planning C: Politics and Space 22, 667-685.

Blythe J, Nash K, Yates J, Cumming G (2017) Feedbacks as a bridging concept for advancing transdisciplinary sustainability research. Current Opinion in Environmental Sustainability 26, 114-119.

Bodin O, Crona BI (2009) The role of social networks in natural resource governance: what relational patterns make a difference. Global Environmental Change 19, 366-374.

Boillat S, Berkes F (2013) Perception and interpretation of climate change among Quechua Farmers of Bolivia: Indigenous Knowledge as a resource for adaptive capacity. Ecology and Society 18(4), 21. 
Bornmann L, Haunschild R, Marx W (2016) Policy documents as sources for measuring societal impact: how often is climate change research mentioned in policy-related documents? Scientometrics 109,1477-1495.

Boykoff MT (2007) From convergence to contention: United States mass media representations of anthropogenic climate change science. Transactions of the Institute of British Geographers 32, 477-489.

Bremer S, Meisch S (2017) Co-production in climate change research: reviewing different perspectives. WIRES Climate Change. DOI: 10.1002/wcc.482.

Bromham L, Dinnage R, Hua X (2016) Interdisciplinary research has consistently lower funding success. Nature 534, 684-687.

Brown LD, Tandon R (1983) Ideology ad political economy in inquiry: action research and participatory research. Journal of Applied Behavioural Science 19, 277-294.

Butler JRA, Suadnya W, Puspadi K, Sutaryono Y, Wise RM, Skewes TD, Kirono D, Bohensky EL, Handayani T, Habibi P, Kisman M, Suharto I, Hanartani, Supartarningsih S, Ripaldi A, Fachry A, Yanuartati Y, Abbas G, Duggan K, Ash A (2014) Framing the application of adaptation pathways for rural livelihoods and global change in eastern Indonesian islands. Global Environmental Change 28, 368-382.

Campbell LM (2005) Overcoming Obstacles to Interdisciplinary Research. Conservation Biology 19, 574-577.

Campos-Arceiz A, Pin Koh L, Primack RB (2013) Are conservation biologists working too hard? Biological Conservation 166, 186-190.

Cash DW, Borck JC, Patt AG (2006) Countering the loading-dock approach to linking science and decision making - Comparatice analysis of El Nino/Southern Oscillation (ENSO) forecasting systems. Science, Technology and Human Values 31, 465-494.

Cash D, Buizer J (2005) Knowledge-action systems for seasonal to interannual climate forecasting: Summary of a workshop. The National Academies Press, Washington, DC, USA.

Cash DW, Clark WC, Alcock F, Dickson NM, Eckley N, Guston DH, Jager J, Mitchell RB (2003) Knowledge systems for sustainable development. Proceedings of the national Academy of Science 100, 8086-8091.

Cash DW, Moser SC (2000) Linking global and local scales: designing dynamic assessment and management processes. Global Environmental Change 10, 109-120.

Cheruvelil KS, Soranno PA, Weathers KC, Hanson PC, Goring SJ, Filstrup CT, et al. (2014) Creating and maintaining high-performing collaborative research teams: the importance of diversity and interpersonal skills. Frontiers in Ecology and the Environment 12, 31-38. 
Cook CN, Mascia MB, Schwartz MW, Possingham HP, Fuller RA (2013) Achieving conservation science the bridges the knowledge-action boundary. Conservation Biology 27, 669-678.

Colvin RM, Witt GB, Lacey J (2015) The social identity approach to understanding sociopolitical conflict in environmental and natural resources management. Global Environmental Change 34, 237-246.

Colvin RM, Witt GB, Lacey J (2016) Approaches to identifying stakeholders in environmental management: Insights from practitioners to go beyond the 'usual suspects'. Land Use Policy 52, 266-276.

Cornell S, Berkhout F, Tuinstra W, Tàbara JD, Jäger J, Chabay I, de Wit B, Langlais R, Mills D, Moll P, Otto IM, Petersen A, Pohl C, van Kerkhoff L (2013) Opening up knowledge systems for better responses to global environmental change. Environmental Science and Policy 28: 60-70.

Cornwall A, Jewkes R (1995) What is Participatory Research? Social Science and Medicine 41 (12):1667-1676.

Crona BI, Bodin O (2006) What you know is who you know? Communication patters among resource extractors as a pre-requisite for co-management. Ecology ad Society 11, 7.

Cvitanovic C, Marshall N, Wilson SK, Dobbs K, Hobday A (2014a) Perceptions of Australian marine protected managers regarding the role, importance, and achievability of adaptation for managing the risks of climate change . Ecology and Society 19(4), 33.

Cvitanovic C, Fulton CJ, Wilson SK, van Kerkhoff L, Cripps IL, Muthiga N (2014b) Utility of primary scientific literature to environmental managers: An international case study on coral-dominated marine protected areas. Ocean and Coastal Management 102, 7278.

Cvitanovic C, Hobday AJ, van Kerkhoff L, Wilson SK, Dobbs K, Marshall NA (2015a) Improving knowledge exchange among scientists and decision-makers to facilitate the adaptive governance of marine resources: a review of knowledge and research needs. Ocean and Coastal Management 112, 25-35.

Cvitanovic C, Hobday AJ, van Kerkhoff L, Marshall NA (2015b) Overcoming barriers to knowledge for adaptive resource management; the perspectives of Australian marine scientists. Marine Policy 52, 38-44.

Cvitanovic C, McDonald J, Hobday AJ (2016) From science to action: Principles for undertaking environmental research that enables knowledge exchange and evidencebased decision-making. Journal of Environmental Management 183, 864-874.

Cvitanovic C, Cunningham R, Dowd AM, Howden SM, van Putten El (2017) Using social network analysis to monitor and assess the effectiveness of knowledge brokers at connecting scientists and decision-makers: As Australian case study. Environmental Policy and Governance DOI: 10.1002/eet.1752. 
Deelstra Y, Nooteboom SG, Kohlmann HR, van den Berg J, Innanen S (2003) Using knowledge for decision-making purpose in the context of large projects in the Netherlands. Environmental Impact Assessment Review 23, 517-541.

Djenontin INS, Meadow AM (2018) The Art of Co-production of Knowledge in Environmental Sciences and Management: Lessons from International Practice. Environmental Management 61, 885-903.

Dilling L, Lemos MC (2011) Creating usable science: opportunities and constraints for climate knowledge use and their implications for science policy. Global Environmental Change 21, 680-689.

Doubleday R, Wilsdon J (2012) Science policy: Beyond the great and good. Nature 485, 301302.

Eckley N (2002) Dependable dynamism lessons for designing scientific assessment processes in consensus negotiations. Global Environmental Change 12, 15-23.

Eckley N, Clark W, Farrell A, Jäger J, Stanners D (2001) Designing effective assessments: The role of participation, science and governance, and focus. EEA, Copenhagen, Denmark.

Emanuel EJ, Wendler D, Grady C (2000) What makes clinical research ethical? Journal of the American Medical Association 283, 2701-2711.

Evans MC, Cvitanovic C (2018) An introduction to achieving policy impact for early career researchers. Palgrave Communications, DOI: 10.1057/s41599-018-0144-2.

Evans MC, Davila F, Toomey A, Wyborn C (2017) Embrace complexity to improve conservation decision making. Nature Ecology \& Evolution, doi:10.1038/s41559-0170345-x.

Farrell AE, Jäger J (2005) Assessments of regional and global environmental risks: Designing processes for the effective use of science in decision-making. RFF Press, Washington, USA.

Fazey I, Fischer J, Lindenmayer DB (2005) What do conservation biologist publish? Biological Conservation 124, 63-73.

Fazey I, Fazey JA, Salisbury JG, Lindenmayer DB, Dovers S (2006) The nature and role of experiential knowledge for environmental conservation. Environmental Conservation 33(1),1-10.

Fazey I, Fazey JA, Fischer J, Sherren K, Warren J, Noss RF, Dovers SR (2007) Adaptive capacity and learning to learn as leverage for social-ecological resilience. Frontiers in Ecology and Environment 5, 375-380.

Fazey I, Schäpke N, Caniglia G, Patterson J, Hultman J, Van Mierlo B, Säwe F, Wiek A, Wittmayer JM, Aldunce P, Al Waer H, Battacharya N, Bradbury H, Carmen E, Colvin J, Cvitanovic C, D'Souza, M, Gopel M, Goldstein B, Hämäläinen T, Harper G, Henfry T, Hodgson A, Howden MS, Kerr A, Klaes M, Lyon C, Midgley G, Moser S, Mukherjee N, 
Müller K, O'Brien K, O'Connell DA, Olsson P, Page G, Reed MS, Searle B, Silvestri G, Spaiser V, Strasser T, Tschakert P, Uribe-Calvo N, Waddell S, Rao-William J, Wise R, Wolstenholme R, Woods M, Wyborn C (2018) Ten essentials for action-oriented and second order energy transitions, transformations and climate change research. Energy Research \& Social Science, Vol 40: 54-70.

Few R (2001) Containment and counter-containment: planner/community relations in conservation planning. The Geographical Journal 167, 111-124.

Few R (2003) Participation or containment? Insights from the planning of protected areas in Belize', in: J. Pugh, R.B. Potter (eds), Participatory Planning in the Caribbean: Lessons from Practice, Ashgate, Aldershot, UK, 23-44.

Few R, Brown K, Tompkins EL (2007) Public participation and climate change adaptation: avoiding the illusion of inclusion. Climate Policy 7, 46-59.

Fielding KS, Hornsey MJ (2016) A social identify analysis of climate change and environmental attitudes and behaviours: Insights and opportunities. Frontiers in Psychology 7, 121.

Fischer J, Gardner TA, Bennett EM, Balvanera P, Biggs R, Carpenter S, Daw T, Folke C, Hill R, Hughes TP, Luthe T, Maass M, Meacham M, Norström A V, Peterson G, Queiroz C, Seppelt R, Spierenburg M, Tenhunen J (2015) Advancing sustainability through mainstreaming a social-ecological systems perspective. Current Opinions in Environmental Sustainability 14, 144-149.

Frusher SD, Hobday AJ, Jennings SM, Creighton C, D'Silva D, Haward M, Holbrook NJ, Nursey-Bray M, Pecl GT, van Putten El (2014) The short history of research in a marine climate change hotspot: from anecdote to adaptation in south-east Australia. Reviews in Fish Biology and Fisheries 24, 593-611.

Gaziulusoy Al, Ryan C, McGrail S, Chandler P, Twomey P (2016) Identifying and addressing challenges faced by transdisciplinary research teams in climate change research. Journal of Cleaner Production 123, 55-64.

Gearheard S, Pocernich M, Stewart R, Sanguya J, Huntington HP (2010) Linking Inuit knowledge and meteorological station observations to understand changing wind patterns at Clyde River, Nunavut. Climate Change 100, 267-294.

Grant J, Nelson G, Mitchell T (2008) Negotiating the challenges of participatory action research: Relationships, power, participation, change and credibility. The SAGE Handbook of Action Research, P. Reason and H. Bradbury (Eds), SAGE Publications Ltd.

Green LW, Glasgow RE, Atkins D, Stange K (2009) Making evidence from research more relevant, useful, and actionable in policy, program planning and practice slips "twixt cup and lip". American Journal of Preventative Medicine 37, S187-S191. 
Greenwood DJ, Levin M (2007) Introduction to action research: Social research for social change. Second Edition, Sage Publications Ltd.

Grose MR, Brown JN, Narse S, Brown JR, Murphy BF, Langlais C, Gupta AS, Moise AF, Irving DB (2014) Assessment of the CMIP5 global climate model simulations of the western tropical Pacific climate system and comparison to CMIP3. International Journal of Climatology 34, 3382-3399.

Gupta J (2016) Climate change governance: history, future, and triple-loop learning. WIREs Climate Change 7, 192-210.

Guston DH (2001) Boundary organizations in environmental policy and science: An introduction. Science, Technology and Human Values 26, 339-408.

Haslam SA, Eggins RA, Reynolds KJ (2003) The ASPIRe model: Actualizing social and personal identify resources to enhance organizational outcomes. Journal of Occupational and Organizational Psychology 76, 83-113.

Haasnoot M, Kwakkel FH, Walker WE, ter Maat J (2013) Dynamic adaptive policy pathways: A method for crafting robust decisions for a deeply uncertain world. Global Environmental Change 23, 485-498.

Harris F, Lyon F (2014) Transdisciplinary environmental research: a review of approaches to knowledge co-production. Nexus Network Think Piece Series, Paper, 2.

Hegger D, Dieperink C (2014) Toward successful joint knowledge production for climate change adaptation: lessons from six regional projects in the Netherlands. Ecology and Society, 19(2), 34.

Hemming C, Burgman MA, Haneea AM, McBride MF, Wintle BC (2017) A practical guide to structured expert elicitation using the IDEA protocol. Methods in Ecology and Evolution 9, 169-180.

Hewitson BC, Daron J, Crane RG, Zermoglio MF, Jack C (2014) Interrogating empiricalstatistical downscaling. Climatic Change 122, 539-554.

Hoeft TJ, Burke W, Hopkins SE, Charles W, Trinidad SB, James RD, Boyer BB (2014) Building partnerships in community-based participatory research: Budgetary and other cost considerations. Health Promotion Practice 15, 263-270.

Howden SM, Soussana JF, Tubiello FN, Chhetri N, Dunlop M, Meinke H (2007) Adapting agriculture to climate change. Proceedings of the National Academy of Sciences of the United States of America 104, 19691-19696.

Howden SM, Schtoeter S, Crimp S, Hanigan I (2014) The changing roles of science in managing Australian droughts: An agricultural perspective. Weather and Climate Extremes 3, 80-89. 
Huntjens P, Eshuis J, Termeer C, van Buuren A (2014) Forms and foundations of action research. Action Research for Climate Change Adaptation: Developing and Applying Knowledge for Governance, A. van Buuren, and M. van Vliet, Eds., Routledge.

IPCC (2014) Climate Change 2014: Impacts, Adaptation, and Vulnerability. Part A: Global and Sectoral Aspects. Contribution of Working Group II to the Fifth Assessment Report of the Intergovernmental Panel on Climate Change [Field, C.B., V.R. Barros, D.J. Dokken, K.J. Mach, M.D. Mastrandrea, T.E. Bilir, M. Chatterjee, K.L. Ebi, Y.O. Estrada, R.C. Genova, B. Girma, E.S. Kissel, A.N. Levy, S. MacCracken, P.R. Mastrandrea, and L.L.White (eds.)]. Cambridge University Press, Cambridge, United Kingdom and New York, NY, USA, 1132 pp.

IPCC, 2018: Summary for Policymakers. In: Global warming of $1.5^{\circ} \mathrm{C}$. An IPCC Special Report on the impacts of global warming of $1.5^{\circ} \mathrm{C}$ above pre-industrial levels and related global greenhouse gas emission pathways, in the context of strengthening the global response to the threat of climate change, sustainable development, and efforts to eradicate poverty [V. Masson-Delmotte, P. Zhai, H. O. Pörtner, D. Roberts, J. Skea, P.R. Shukla, A. Pirani, W. Moufouma-Okia, C. Péan, R. Pidcock, S. Connors, J. B. R. Matthews, Y. Chen, X. Zhou, M. I. Gomis, E. Lonnoy, T. Maycock, M. Tignor, T. Waterfield (eds.)]. World Meteorological Organization, Geneva, Switzerland, 32 pp.

Jacobs K (2014) Lessons from the National Climate Assessment on science translation and boundary organizations. US Clivar Variations 12 (4), 1-4.

Jacobson N, Butterill D, Goering P (2004) Organizational factors the influence universitybased researchers' engagement in knowledge transfer activities. Science Communication 25, 246-259.

Jasanoff S (2004) States of knowledge: the co-production of science and social order. Routledge, London, UK.

Kahan D (2010) Fixing the communications failure. Nature 463, 296-297.

Keeler BL, Chaplin-Kramer R, Guerry AD, Addison PFE, Bettigole C, Burke IC, Gentry B, Chambliss L, Young C, Travis AJ, Darimont ST, Gordon DR, Hellmann J, Kareiva P, Monfort S, Olander L, Profeta T, Possingham HP, Slotterback C, Sterling E, Ticktin T, Vira B (2017) Society is ready for a new kind of science - Is academia? Bioscience 67, 591-592.

Khanlou N, Peter E (2005) Participatory action research: considerations for ethical review. Social Science and Medicine 60, 2333-2340.

King TK, O'Meara D (2018) 'The people have spoken': how cultural narratives politically trumped the best available science (BAS) in managing the Port Phillip Bay fishery in Australia. Maritime Studies, doi.org/10.1007/s4015. 
Klenk N, Fiume A, Meehan K, Gibbes C (2017) Local knowledge in climate adaptation research: moving knowledge frameworks from extraction to co-production. Wiley Interdisciplinary Reviews: Climate Change 8(5), e475.

Kleppa E, Sanne B, Tell GS (2008) Working overtime is associated with anxiety and depression: the Hordaland Health Study. Journal of Occupational and Environmental Medicine 50, 658-666.

Lacey J, Howden SM, Cvitanovic C, Dowd AM (2015) Informed adaptation: Ethical considerations for adaptation researchers and decision-makers. Global Environmental Change 32, 200-210.

Lacey J, Howden M, Cvitanovic C, Colvin RM (2018) Understanding and managing trust at the climate science-policy interface. Nature Climate Change 8, 22-28.

Lang DJ, Wiek A, Bergmann M, Stauffacher M, Martens P, Moll P, Swilling M, Thomas CJ (2012) Transdisciplinary research in sustainability science: practice, principles and challenges. Sustainability Science 7, 25-43.

Lemos MC, Arnott JC, Ardoin NM, Baja K, Bednarek AT, Dewulf A, Fieseler C, Goodrich KA, Jagannathan K, Klenk K, MachKJ, Meadow AM, Meyer R, Moss R, Nichols L, Sjostrom D, Stults M, Turnhout E, Vaughan C, Wong-Parodi G, Wyborn C (2018) To co-produce or not to co-produce. Nature Sustainability 1, 722-724.

Lewin K (1946) Action research and minority problems. Journal of Social Issues 46, 34-46.

Linklater WL (2003) Science and management in a conservation crisis: A case study with rhinoceros. Conservation Biology 17, 968-975.

Lubchenco J (1998) Entering the century of the environment: a new social contract for science. Science $279,491-497$.

Mackewn J (2008) Facilitation as Action Research in the Moment. The SAGE Handbook of Action Research, P. Reason, and H. Bradbury, Eds., SAGE Publications Ltd.

Margerum RD (2002) Evaluating Collaborative Planning: Implications from an Empirical Analysis of Growth Management. Journal of the American Planning Association 68, 179-193.

Martin TG, Burgman MA, Fidler F, Kuhnert PM, Low-Choy S, McBride M, Mengersen K (2012) Eliciting expert knowledge in Conservation Science. Conservation Biology 26, 29-38.

Mauser W, Klepper G, Rice M, Schmalzbauer BS, Hackmann H, Leemand R, Moore H (2013) Transdisciplinary global change research: the co-creation of knowledge for sustainability. Current Opinions in Environmental Sustainability 5, 420-431. 
Meadow AM, Ferguson DB, Guido Z, Horangic A, Owen G (2015) Moving toward the deliberate co-production of climate science knowledge. Weather, Climate and Society 7, 179-191.

Meinke H, Howden SM, Struik PC, Nelson R, Rodriguez D, Chapman SC (2009) Adaptation science for agriculture and natural resource management- urgency and theoretical basis. Current Opinions in Environmental Sustainability 1, 69-76.

Meyer M (2010) The rise of the knowledge broker. Science Communication 32, 118-127.

Millar RJ, Fuglestvedt JS, Friedlingstein P, Rogelj J, Grubb MJ, Matthews HD, Skeie RB, Forster PM, Frame DJ, Allen MR (2017) Emission budgets and pathways consistent with limting warming to $1.5^{\circ} \mathrm{C}$. Nature Geoscience $10,741-747$.

Mols F, Haslam SA, Jetten J, Steffens NK (2014) Why a nudge is not enough: A social identify critique of governance by stealth. European Journal of Political Research 54, 81-98.

Naess LO (2012) The role of local knowledge in adaptation to climate change. WIREs Climate Change 4, 99-106.

Newig J, Günther D, Pahl-Wostl C (2010) Synapses in the network: learning in governance in the context of environmental management. Ecology and Society 15(4), 24.

Nicholls RJ, Cazenave A (2010) Sea-level rise and its impact on coastal zones. Science 328, 1517-15-20.

O'Leary BC, Kvist K, Bayliss HR, Derroire G, Healey JR, Hughes K, Kleinschroth F, Sciberras M, Woodcock P, Pullin AS (2016) The reliability of evidence review methodology in environmental science and communication. Environmental Science and Policy 64, 7582.

Park P, Brydon-Miller M, Hall B, Jackson T (1993) (Eds) Voices of change: participatory research in the United States and Canada. Ontario Institute for Studies in Education Press, Toronto, Canada.

Parrott L, Meyer WS (2012) Future landscape: managing within complexity. Frontiers in Ecology and Environment 10, 382-389.

Pecl GT, Araújo MB, Bell JD, Blanchard J, Bonebrake TC, Chen IC, Clark TD, Colwell RK, Danielsen F, Evengård B, Falconi L, Ferrier S, Frusher S, Garcia RA, Griffis RB, Hobday AJ, Janion-Scheepers C, Jarzyna MA, Jennings S, Lenoir J, Linnetved HI, Martin VY, McCormack PC, McDonald J, Mitchell NJ, Mustonen T, Pandolfi JM, Pettorelli N, Popova E, Robinson SA, Scheffers BR, Shaw JD, Sorte CJB, Strugnell JM, Sunday JM, Tuanma MN, Vergés A, Villanueva C, Wernberg T, Wapstra E, Williams SE (2017) Biodiversity redistribution under climate change: Impacts on ecosystems and human well-being. Science 355, DOI: 10.1126/science.aai9214 
Picketts IM (2018) The best laid plans: Impacts of politics on local climate change adaptation. Environmental Science and Policy 87, 26-32.

Pielke Jr RA (2007) The honest broker: Making sense of science in policy and politics. Cambridge, Cambridge University Press.

Polanyi M, Cockburn L (2003) Opportunities and Pitfalls of Community-Based Research: A Case Study. Michigan Journal of Community Service Learning, Spring, 16-25.

Polk M (2015) Transdisciplinary co-production: Designing and testing a transdisciplinary research framework for societal problem solving. Futures 65, 110-122.

Rafols I, Leydesdorff L, O'Hare A, Nightingale P, Stirling A (2012) How journal rankings can suppress interdisciplinary research: A comparison between Innovation Studies and Business \& Management. Research Policy 41, 1262-1282.

Ramirez-Villegas J, Challinor AJ, Thornton PK, Jarvis A (2013) Implications of regional improvement in global climate models for agriculture impact research. Environmental Research Letters 8, 024018.

Reason P, Bradbury H (Eds.) (2008a) The SAGE Handbook of Action Research. SAGE Publications Ltd.

Reason P, Bradbury H (Eds.) (2008b) Introduction. The SAGE Handbook of Action Research, P. Reason, and H. Bradbury, Eds., SAGE Publications, 1-10.

Reed MS (2008) Stakeholder participation for environmental management: a literature review. Biological Conservation 141, 2417-2431.

Reed MS (2016) The Research Impact Handbook. Fast Track Impact Pty Ltd, Aberdeenshire, UK.

Reed MS, Stringer LC, Fazey I, Evely AC, Kruijsen JHJ (2014) Five principles for the practice of knowledge exchange in environmental management. Journal of Environmental Management 146, 337-345.

Reed MS, Vella S, Challies E, de Vente J, Frewer L, Hohenwallner-Ries D, Huber T, Neumann RK, Oughton EA, del Ceno JS, van Delden H (2017) A theory of participation: what makes stakeholder and public engagement in environmental management work. Restoration Ecology 26, S7-S17.

Reevy, GM \& Deason, G (2014) Predictors Of Depression, Stress, And Anxiety Among NonTenure Track Faculty. Frontiers In Psychology 5, DOI: 10.3389/fpsyg.2014.00701.

Reid H, Alam M, Berger R, Cannon T, Huq S, Milligan A eds (2009) Community-based adaptation to climate change, participatory learning and action 60. IIED, London, UK. 
Reinecke $S$ (2015) Knowledge brokerage designs and practices in four European climate services: A role model for biodiversity hotspots? Environmental Science and Policy 54, 513-521.

Runhaar H, Wilk B, Persson Å, Uittenbroek C, Wamsler C (2018) Mainstreaming climate adaptation: taking stock about "what works" from empirical research worldwide. Regional Environmental Change 18, 1201-1210.

Salter J, Robinson J, Wiek A (2010) Participatory methods of integrated assessment - A review. WIREs Climate Change 1, 697-717.

Sardar Z (2010) Welcome to postnormnal times. Futures 42, 435-444.

Sarkki S, Niemela J, Tinch R, Van den Hove S, Watt A, Young J (2014) Balancing credibility, relevance and legitimacy: A critical assessment of trade-offs in science-policy interfaces. Science and Public Policy 41, 194-206.

Schensul SL, Schensul JJ, Singer M, Weeks M, Brault M (2014) Participatory Methods and Community-Based Collaborations. Handbook of Methods in Cultural Anthropology, 2 ed., H. R. Bernard, and C. C. Gravlee, Eds., Rowman \& Littlefield Publishers, 178-204.

Schulz AJ, Israel BA, Lantz P (2003) Instrument for evaluating dimensions of group dynamics within community-based participatory research partnerships. Evaluation and Program Planning 26 (3), 249-262.

Slovic, P (1987) Perception of Risk. Science 236, 280-285.Supran G, Oreskes N (2017) Assessing ExxonMobil's climate change communications (1977-2014). Environmental Research Letters 12, 084019.

Tai APK, Val Martin M, Heald CL (2014) Threat to future global food security from climate change and ozone air pollution. Nature Climate Change 4, 817-821.

Tax S (1958) The Fox Project. Human Organization 17, 17-19.

Tengö M, Hill R, Malmer P, Raymond CM, Spierenburg M, Danielson F, Elmqvist T, Folke C (2017). Weaving knowledge systems in IPBES, CBD and beyond - lessons learned for sustainability. Current Opinions in Environmental Sustainability 26-27, 17-25.

Timmings C, Khan S, Moore JE, Marquez C, Pyka K, Straus SE (2016) Ready, Set, Change! Development and usability testing of an online readiness for change decision support tool for healthcare organizations. BMC Medical Informatics and Decision Making 16, 24.

Trimble M, Lázaro M (2014) Evaluation Criteria for Participatory Research: Insights from Coastal Uruguay. Environmental Management 54, 122-137.

Van Kerkhoff L, Lebel L (2015) Coproductive capacities: rethinking science-governance relations in a diverse world. Ecology and Society 20(1), 14. 
281

Van Kerkhoff L, Pilbeam (2017) Understanding socio-cultural dimensions of environmental decision-making: A knowledge governance approach. Environmental Science and Policy 73, 29-37.

Virtanen M, Ferrie JE, Singh-Manoux A, Shipley MJ, Stansfeld SA, Marmot MG, Ahola K, Vahtera J, Kivimäki M (2011) Long working hours and symptons of anziety and depression: a 5-year follow-up of the Whitehall II study. Psychological Medicine 41, 5485-2494.

Wallerstein NB, Duran B (2008) The Theoretical, Historical, and Practice Roots of CBPR. Community-Based Participatory Research for Health: From Process to Outcomes, M. Minkler, and N. B. Wallerstein, Eds., John Wiley \& Sons, 25-46.

Watermeyer R, Hedgecoe A (2016) Selling 'impact': peer reviewer projections of what is needed and what counts in REF impact case studies. A retrospective analysis. Journal of Education Policy 31, 651-665.

Wheeler T, von Braun J (2013) Climate change impacts on global food security. Science 341, 508-513.

Wiber M, Berkes F, Charles A, Kearney J (2004) Participatory research supporting community-based fishery management. Marine Policy 28, 459-468.

Wiek A, Withycombe L, Redman CL (2011) Key competencies in sustainability: a reference framework for academic program development. Sustainability Science 6, 203-218.

Wise RM, Fazey I, Stafford Smith M, Park SE, Eakin HC, Archer Van Garderen ERM, Campbell B (2014) Reconceptualising adaptation to climate change as part of pathways of change and response. Global Environmental Change 28, 325-336.

Wyborn CA (2015) Connecting knowledge with actions through coproductive capacities: adaptive governance and connectivity conservation. Ecology and Society 20(1), 11. 